\title{
Quality aspects of the Wegener Center multi-satellite GPS radio occultation record OPSv5.6
}

\author{
Barbara Angerer ${ }^{1,2}$, Florian Ladstädter ${ }^{1,2}$, Barbara Scherllin-Pirscher ${ }^{3}$, Marc Schwärz ${ }^{1,2}$, Andrea K. Steiner ${ }^{1,2}$, \\ Ulrich Foelsche $^{2,1}$, and Gottfried Kirchengast ${ }^{1,2}$ \\ ${ }^{1}$ Wegener Center for Climate and Global Change (WEGC), University of Graz, Graz, Austria \\ ${ }^{2}$ Institute for Geophysics, Astrophysics, and Meteorology/Institute of Physics, University of Graz, Graz, Austria \\ ${ }^{3}$ Zentralanstalt für Meteorologie und Geodynamik (ZAMG), Vienna, Austria
}

Correspondence: Barbara Angerer (barbara.angerer@uni-graz.at)

Received: 5 July 2017 - Discussion started: 7 July 2017

Revised: 2 November 2017 - Accepted: 6 November 2017 - Published: 13 December 2017

\begin{abstract}
The demand for high-quality atmospheric data records, which are applicable in climate studies, is undisputed. Using such records requires knowledge of the quality and the specific characteristics of all contained data sources. The latest version of the Wegener Center (WEGC) multisatellite Global Positioning System (GPS) radio occultation (RO) record, OPSv5.6, provides globally distributed upperair satellite data of high quality, usable for climate and other high-accuracy applications. The GPS RO technique has been deployed in several satellite missions since 2001. Consistency among data from these missions is essential to create a homogeneous long-term multi-satellite climate record. In order to enable a qualified usage of the WEGC OPSv5.6 data set we performed a detailed analysis of satellite-dependent quality aspects from 2001 to 2017. We present the impact of the OPSv5.6 quality control on the processed data and reveal time-dependent and satellite-specific quality characteristics. The highest quality data are found for MetOp (Meteorological Operational satellite) and GRACE (Gravity Recovery and Climate Experiment). Data from FORMOSAT-3/COSMIC (Formosa Satellite mission-3/Constellation Observing System for Meteorology, Ionosphere, and Climate) are also of high quality. However, comparatively large day-to-day variations and satellite-dependent irregularities need to be taken into account when using these data. We validate the consistency among the various satellite missions by calculating monthly mean temperature deviations from the multisatellite mean, including a correction for the different sampling characteristics. The results are highly consistent in the altitude range from 8 to $25 \mathrm{~km}$, with mean temperature de-
\end{abstract}

viations less than $0.1 \mathrm{~K}$. At higher altitudes the OPSv5.6 RO temperature record is increasingly influenced by the characteristics of the bending angle initialization, with the amount of impact depending on the receiver quality.

\section{Introduction}

Detailed knowledge of the characteristics and the quality of data is essential for their qualified usage in atmospheric research. This also applies to the use of Global Positioning System (GPS) radio occultation (RO) data, which play a major role in the characterization of the free atmosphere (Anthes, 2011). GPS RO is a limb-sounding satellite technique, which has continuously provided atmospheric profiles since 2001 . The technique uses the signal transmitted by Global Navigation Satellite System (GNSS) satellites (in this work we only use RO data from GPS satellites) and received by low Earth orbit (LEO) satellites to probe the Earth's atmosphere.

The GPS signals are emitted at two radio frequencies in the $\mathrm{L}$ band (wavelengths of about $20 \mathrm{~cm}$ ) and refracted on their way through the atmosphere. The LEO receiver measures the excess phase path due to the Earth's refractivity field, which is proportional to density in regions where humidity is negligible. Due to the relative motion of the satellites, the atmosphere is scanned vertically, either from the top downwards for setting occultations (satellites move away from each other) or from the bottom up for rising occultations (satellites move towards each other). 
An RO event lasts about 1 to 2 min. Since the basic measurement of RO is the signal phase as function of time, external calibration is not needed and only short-term measurement stability is required over an RO event, which is ensured by the utilization of highly stable oscillators. The traceability to the international time standard (SI second) ensures longterm stability, which is an essential prerequisite for climate applications (Leroy et al., 2006; Ohring et al., 2005).

The technique was first exploited in 1995 with the proofof-concept mission Global Positioning System/Meteorology (GPS/Met). The highest-quality data are obtained in the upper troposphere to lower stratosphere (UTLS) region (Scherllin-Pirscher et al., 2011b). Global coverage, longterm stability, high vertical resolution, and weather independence due to the GPS frequency in the microwave domain are further advantages (Kursinski et al., 1997). With these properties GPS RO has a significant impact on numerical weather prediction (e.g. Healy and Thépaut, 2006; Cucurull and Derber, 2008) and on our ability to monitor the atmospheric climate system (Anthes, 2011; Steiner et al., 2011).

For climate applications, data consistency and quality are essential for producing a homogeneous long-term multisatellite record. Due to the self-calibrating nature of GPS $\mathrm{RO}$, data from different RO missions and different sensor types can be combined into a consistent multi-satellite climate record if the same processing system is used (Hajj et al., 2004; Schreiner et al., 2007; Foelsche et al., 2011).

Hajj et al. (2004) showed that data from the CHAMP (Challenging Minisatellite Payload) mission and SAC-C (Satélite de Aplicaciones Científicas-C) are remarkably consistent. Schreiner et al. (2010) compared co-located profiles from FORMOSAT-3/COSMIC (Formosa Satellite mission3/Constellation Observing System for Meteorology, Ionosphere, and Climate; F3C hereafter) satellites and confirmed that the root mean square difference between 10 and $20 \mathrm{~km}$ altitude is less than $0.2 \%$ in refractivity. Foelsche et al. (2011) showed that refractivity and temperature climate records from multiple RO missions are consistent within $0.05 \%$ if the same processing scheme is applied.

Differences in the processing methods lead to structural uncertainties. This has been investigated in detail for RO data from CHAMP, processed by six different RO data centres (Ho et al., 2012; Steiner et al., 2013) finding high intercentre consistency, especially in the altitude range of about 8 to $25 \mathrm{~km}$ altitude and within latitudes from $50^{\circ} \mathrm{S}$ and $50^{\circ} \mathrm{N}$.

Besides the importance of consistent RO data, validating the quality of the individual satellite data is essential to identify the atmospheric profiles with reduced quality and to ensure the suitability of the data set for climate applications.

In this paper we focus on the description of the Wegener Center (WEGC) RO record Occultation Processing System version 5.6 (OPSv5.6) in terms of data quality and multisatellite consistency. An overview of the data used in the OPSv5.6 retrieval is given in Sect. 2. In Sect. 3 we focus on the retrieval methods and the quality control conducted during the retrieval. The data quality of individual satellite missions is discussed in Sect. 4, and Sect. 5 describes the steps towards a combined multi-satellite record. A summary and the main conclusions are given in Sect. 6.

\section{RO data}

WEGC OPSv5.6 uses amplitude and excess phase data as well as precise orbit information (position and velocity vectors for both the GPS and the LEO satellite) from the University Corporation of Atmospheric Research/COSMIC Data Analysis and Archive Center (UCAR/CDAAC) as input data for the retrieval of atmospheric variables. Data from CHAMP, SAC-C, GRACE (Gravity Recovery and Climate Experiment), C/NOFS (Communications/Navigation Outage Forecasting System), MetOp (Meteorological Operational satellite) and $\mathrm{F} 3 \mathrm{C}$ have been processed. Depending on the availability at the UCAR/CDAAC data archive, reprocessed, or post-processed data are used.

The German mission CHAMP, operated by the HelmholtzZentrum Potsdam/German Research Center for Geosciences (GFZ) and launched in 2000, was the first mission to provide a continuous multi-year RO record (May 2001 to October 2008) (Wickert et al., 2001). The mission was equipped with the GPS receiver BlackJack, also referred to as TRSR-2 (TurboRogue Space Receiver 2), produced by the Jet Propulsion Laboratory (JPL). The receiver was a new-generation instrument of the GPS/Met receiver TRSR and was able to track around 250 setting RO events per day.

The US/Argentinian mission SAC-C (Hajj et al., 2004) was in orbit from 2000 to 2013 and had the same BlackJack receiver mounted as CHAMP, although it was named GPS occultation and passive reflection experiment (GOLPE). However, SAC-C was the first mission where open-loop (OL) tracking was implemented, which also enabled the acquisition of rising signals for the first time (Ao et al., 2009). The ability to track the GPS signal during rising occultations significantly increases the number of observations.

The two satellites of the joint US/German twin-satellite mission GRACE (Beyerle et al., 2005; Wickert et al., 2005) were launched in 2002 into the same polar orbit with the main focus of observing the Earth's time-variable gravity field. Both satellites (GRACE-A and GRACE-B) carry a modified version of the BlackJack receivers used on CHAMP and SAC-C. RO measurements have been taken by GRACE-A since 2006, when the receiver was switched on permanently. GRACE-B only provides measurements for some shorter time periods (July-December 2014, JuneOctober 2015, and April-September 2016) when swapping manoeuvres took place, making GRACE-B the trailing satellite.

The major aim of the US C/NOFS mission (de la Beaujardière et al., 2004) was the monitoring of ionospheric scintillation, but RO measurements were also taken. The mis- 
Table 1. Excess phase and orbit input data to the WEGC OPSv5.6 radio occultation data processing. Regarding the differencing methods, SD denotes single differencing and ZD denotes zero differencing.

\begin{tabular}{|c|c|c|c|c|c|}
\hline Mission & Launch & GPS receiver & UCAR processor version & Time period & Differencing method \\
\hline CHAMP & 2000 & BlackJack & 2014.0140 & $2001-05-18$ to $2008-10-05$ & SD \\
\hline \multirow[t]{2}{*}{ GRACE } & 2002 & BlackJack & 2010.2640 & $2007-02-28$ to $2014-03-30$ & SD \\
\hline & & & 2014.2760 & $2014-03-31$ to $2017-02-28$ & $\mathrm{ZD}$ \\
\hline \multirow[t]{3}{*}{ SAC-C } & 2000 & BlackJack & 2005.3090 & $2001-08-13$ to $2002-10-14$ & SD \\
\hline & & & 2005.1720 & $2002-11-03$ to $2002-11-15$ & \\
\hline & & & 2010.2640 & $2006-03-09$ to $2011-08-03$ & \\
\hline C/NOFS & 2008 & CORISS & 2010.2640 & $2010-03-01$ to $2011-12-31$ & SD \\
\hline MetOp-A & 2006 & GRAS & 2016.0120 & $2007-09-30$ to $2017-02-28$ & $\mathrm{ZD}$ \\
\hline MetOp-B & 2012 & GRAS & 2016.0120 & $2013-02-01$ to $2017-02-28$ & $\mathrm{ZD}$ \\
\hline \multirow[t]{3}{*}{ F3C FM1 } & 2006 & IGOR & 2013.3520 & $2006-04-23$ to $2014-04-30$ & SD \\
\hline & & & 2014.2050 & $2014-05-30$ to $2014-06-29$ & \\
\hline & & & 2014.2860 & $2014-05-01$ to $2017-02-28$ & \\
\hline \multirow[t]{2}{*}{ F3C FM2 } & 2006 & IGOR & 2013.3520 & $2006-05-01$ to $2014-04-30$ & SD \\
\hline & & & 2014.2860 & $2014-05-01$ to $2016-09-23$ & \\
\hline F3C FM3 & 2006 & IGOR & 2013.3520 & $2006-04-24$ to $2010-07-05$ & SD \\
\hline \multirow[t]{3}{*}{ F3C FM4 } & 2006 & IGOR & 2013.3520 & $2006-04-22$ to $2014-04-30$ & SD \\
\hline & & & 2014.2050 & 2014-06-01 to 2014-06-29 & \\
\hline & & & 2014.2860 & $2014-05-01$ to $2015-07-07$ & \\
\hline \multirow[t]{3}{*}{ F3C FM5 } & 2006 & IGOR & 2013.3520 & $2006-04-28$ to $2014-04-30$ & SD \\
\hline & & & 2014.2050 & $2014-06-01$ to $2014-06-27$ & \\
\hline & & & 2014.2860 & $2014-05-01$ to $2016-04-16$ & \\
\hline \multirow[t]{3}{*}{ F3C FM6 } & 2006 & IGOR & 2013.3520 & $2006-04-22$ to $2014-04-30$ & SD \\
\hline & & & 2014.2050 & $2014-06-01$ to $2014-06-29$ & \\
\hline & & & 2014.2860 & $2014-04-30$ to $2017-02-28$ & \\
\hline
\end{tabular}

sion operated between 2008 and 2015; however RO data at UCAR/CDAAC are only available for some months in 2010 and 2011. The orbit design of the C/NOFS mission was chosen such that mostly the tropical regions were covered (inclination of $13^{\circ}$ ). The GPS receiver utilized on C/NOFS, called CORISS (C/NOFS Occultation Receiver for Ionospheric Sensing and Specification), is also of TRSR heritage.

The six identical spacecrafts of the Taiwanese/US F3C mission were launched in April 2006, and since June 2006 UCAR/CDAAC has continuously provided occultation measurements for F3C (Anthes et al., 2008). Each satellite is equipped with an IGOR (Integrated GPS Occultation Receiver), which is also based on the design of the JPL BlackJack receiver and is capable of tracking both setting and rising occultations, yielding around 500 tracked RO events per day.

The MetOp series (Luntama et al., 2008), operated by the European Organisation for the Exploitation of Meteorological Satellites (EUMETSAT), consists of three satellites, with two satellites (MetOp-A and MetOp-B) currently in orbit (by mid-2017). MetOp-A has been providing RO data since the end of 2007 and MetOp-B since spring 2013. Both satellites are circulating in a sun-synchronous, $98^{\circ}$ inclined orbit and carry a GNSS receiver for Atmospheric Sounding (GRAS), which was jointly developed by Saab Ericsson Space (SES) of Sweden and Austrian Aerospace (AAE), now
RUAG Space. The four dual-frequency channels of GRAS allow two rising and two setting events to be tracked simultaneously, yielding a comparatively high number of around 700 observed RO events per day.

Table 1 lists the UCAR/CDAAC data used for the WEGC OPSv5.6 record, the UCAR/CDAAC data versions and available time periods as well as their launch dates, the mounted receiver and the differencing method applied to remove clock errors. The latest WEGC-processed month is currently February 2017; however the OPSv5.6 record will be extended based on new UCAR/CDAAC data becoming available.

By mid-2017, only GRACE, both MetOp satellites and two out of six F3C satellites (F3C FM1 and F3C FM6) are still providing data. With the impending end of the F3C mission, new missions providing $\mathrm{RO}$ data are urgently needed. The succession mission of $\mathrm{F} 3 \mathrm{C}$, named FORMOSAT-7/COSMIC-2 is scheduled to be launched in early 2018. For a better coverage of the tropics, the FORMOSAT-7/COSMIC-2 mission will have a constellation of six satellites at $24^{\circ}$ inclined orbits. In addition, six satellites are planned in a near-polar orbit with a $72^{\circ}$ inclination (Schreiner, 2016). The designated end of lifetime of the GRACE mission is in late 2017. However, the launch period for the GRACE-FO (GRACE Follow-On) mission will be between December 2017 and February 2018, with first 
data available approximately 3 months after the launch, leaving the data gap comparatively small. The launch of the third satellite of the MetOp series, MetOp-C, is currently planned for October 2018.

Furthermore, the Chinese FengYun-3 (FY-3) meteorological satellite series and commercial missions are expected to provide $\mathrm{RO}$ data to the international scientific and operational community soon. FY-3C was launched in 2013 and FY-3D is scheduled for launch in November 2017. Both missions carry the GNSS radio occultation sounder GNOS (Liao et al., 2016; Bai et al., 2017). Together with the planned exploitation of GNSS signals from the Russian GLONASS, the European Galileo system, and the Chinese BeiDou system this will enhance the number of RO observations in the future.

\section{RO retrieval and quality control}

In the following we describe the WEGC OPSv5.6 retrieval processing chain and the approach to assess the quality of the retrieved atmospheric parameters.

\subsection{OPSv5.6 retrieval}

OPSv5.6 includes a combined geometrics optics (GO)/wave optics (WO) retrieval of bending angle profiles, with transition from GO to WO near or somewhat below the tropopause. A combined GO/WO bending angle retrieval approach yielding a vertical stratospheric resolution of 0.5 to $1 \mathrm{~km}$ and low noise level is suitable for the targeted OPSv5.6 data usage purposes.

Input data are UCAR/CDAAC excess phase and amplitude profiles from occulted GNSS signals as well as precise orbit data of the GPS and LEO satellites. To reconstruct excess phases in the lower troposphere, navigation message information is also used from UCAR/CDAAC. Detailed information on the OPSv5.6 retrieval chain was recently given by Schwärz et al. (2016); here we summarize the steps and related key aspects relevant for the quality analysis of this study.

In a first step, quality checks are performed, which comprise technical aspects and consistency of the input data (see Sect. 3.2 for more details). Before entering the bending angle retrieval, the excess phase is filtered using a regularization filtering method, with identical filter settings for all RO missions. Thereafter the bending angle is calculated separately for the two GPS signal frequencies L1 $(1575.42 \mathrm{MHz})$ and L2 $(1227.60 \mathrm{MHz})$ after calculating Doppler profiles from the excess phases (e.g. Melbourne et al., 1994; Kursinski et al., 1997). Subsequently the ionospheric influence on the excess phase measurement is removed by applying the ionospheric correction where the L1 and L2 bending angle profiles are linearly combined (Vorob'ev and Krasil'nikova, 1994). This yields the ionosphere-corrected bending angle profile. The tropospheric bending angle is obtained from a
WO retrieval following Gorbunov (2002) and Gorbunov and Lauritsen (2004). The transition from a GO to WO bending angle is between 7 and $13 \mathrm{~km}$.

To validate the quality of the retrieved bending angle in the upper atmosphere where the contribution from the neutral atmosphere is small, the bending angle bias and noise are determined between 65 and $80 \mathrm{~km}$ (Li et al., 2015). The bending angle bias is defined as the difference between the mean ionosphere-corrected $\mathrm{RO}$ bending angle and the mean mass spectrometer and incoherent scatter radar (MSIS) bending angle in this height layer (Pirscher, 2010). The MSIS reference climatology is used with fixed solar activity to avoid the influence of solar variations. The bending angle bias (with respect to MSIS) is usually slightly negative, with typical values of about $-0.1 \mu \mathrm{rad}$ (Danzer et al., 2013). Large systematic biases of the bending angle can indicate systematic errors in the satellites' orbits, velocities, clock bias estimates, or incomplete removal of the ionospheric contribution to the measurement (Kursinski et al., 1997; Danzer et al., 2013).

Bending angle noise between 65 and $80 \mathrm{~km}$ is defined as the standard deviation of the difference between the ionosphere-corrected RO bending angle and the MSIS bending angle shifted by the bias (Pirscher, 2010; Li et al., 2015). Typically, bending angle noise is smaller than $5 \mu \mathrm{rad}$. Larger bending angle noise can result from measurement noise due to poor GPS receiver quality on board the LEO satellite, large residual ionospheric noise from ionospheric irregularities, or from the differencing method used to remove clock errors (e.g. Gorbunov, 2002; Gobiet et al., 2007). The latter is already applied to raw measurement data at UCAR/CDAAC.

Table 1 shows that single differencing (SD) has been applied to most satellite data used in this study. SD involves another (second) GNSS satellite as reference link (Schreiner et al., 2010), which adds additional ionospheric noise. If ultra-stable oscillators are used on board the LEO satellite (like on GRACE or MetOp), clock errors are so small that high-quality data can be obtained with zero differencing (ZD), which avoids additional ionospheric noise (Beyerle et al., 2005); for more details and comparisons of both methods see, e.g. Schreiner et al. (2010) and Bai et al. (2017).

The next retrieval step relates the bending angle to the refractivity by using an Abel transform. Since this integral transform extends to infinity, initialization at high altitudes is needed. We use co-located ECMWF short-range forecasts, and MSIS above the uppermost ECMWF level for the bending angle initialization. Using ECMWF forecasts (24 and $30 \mathrm{~h}$ ) instead of, for example, ECMWF analyses, prevents the direct impact of assimilated RO data on the high-altitude initialization. The forecast range of at least a day is sufficient to make the a priori information decorrelated from the analyses information. These co-located ECMWF profiles are extracted from the model by using the time layer closest to the mean event time and interpolated to the mean RO event location. Hence the OPSv5.6 RO data are not completely independent from ECMWF at high altitudes. The weight 
of the RO measurement relative to the background information is determined based on the quality of the retrieved ionosphere-corrected RO bending angle. The statistical optimization uses an inverse covariance weighting technique (Gobiet and Kirchengast, 2004; Gobiet et al., 2007) and is performed between 30 and $120 \mathrm{~km}$ impact altitude.

The ratio of the retrieval error (influenced by both the observational and background error) and the error of the background determines the amount of background information contained in the statistically optimized profile. This ratio is denoted by a retrieval to a priori error ratio (RAER), and the impact altitude where this ratio reaches $50 \%$ is called zRAER50. Since the estimated observational error is a constant absolute value, the value of the zRAER50 is driven by its magnitude and the background error, a constant relative value (Gobiet et al., 2007). It indicates the transition altitude between background- and observation-dominated height regions. In the case of small observational errors the observation-dominated region will extend higher up into the stratosphere. For more details see Rieder and Kirchengast (2001).

Recently the observation-to-background weighting ratio (rOBW) has been introduced as a quantity that more directly reflects the fraction of observational information ( $\mathrm{Li}$ et al., 2015; Schwarz et al., 2017). However, zRAER50 as used in OPSv5.6 is still a valuable indicator of the fractionation of information, in particular for inter-comparing different missions.

After the statistical optimization and the retrieval of refractivity profiles, atmospheric variables are calculated. Neglecting the atmospheric wet term, dry density is calculated from atmospheric refractivity by applying the Smith-Weintraub formula (Smith and Weintraub, 1953). Dry pressure profiles are then retrieved using the hydrostatic equation and dry temperature profiles are subsequently obtained by the application of the ideal gas law (Kursinski et al., 1997).

The retrieval of the wet (physical) atmospheric variables is done in a simple version of the 1D-Var retrieval, where a priori knowledge of the state of the atmosphere is required. Co-located ECMWF short-range forecast profiles are again used as background data. A more detailed description of the OPSv5.6 retrieval can be found in Schwärz et al. (2016).

\subsection{OPSv5.6 quality control}

Quality assessment of the WEGC OPSv5.6 data is done in three major steps, as illustrated in Fig. 1. First, the quality of the UCAR/CDAAC input data is checked prior to the bending angle retrieval to ensure that the retrieval can be performed. The input quality control (QC) rejects measurements if the accuracy of the time vector is not within $0.002 \mathrm{~s}$. Furthermore the signal duration must be greater than $15 \mathrm{~s}$ and the straight-line tangent point of the occultation event has to be available within 20 and $65 \mathrm{~km}$ impact altitude, otherwise the profile will be discarded.

\section{OPSv5.6 quality control}

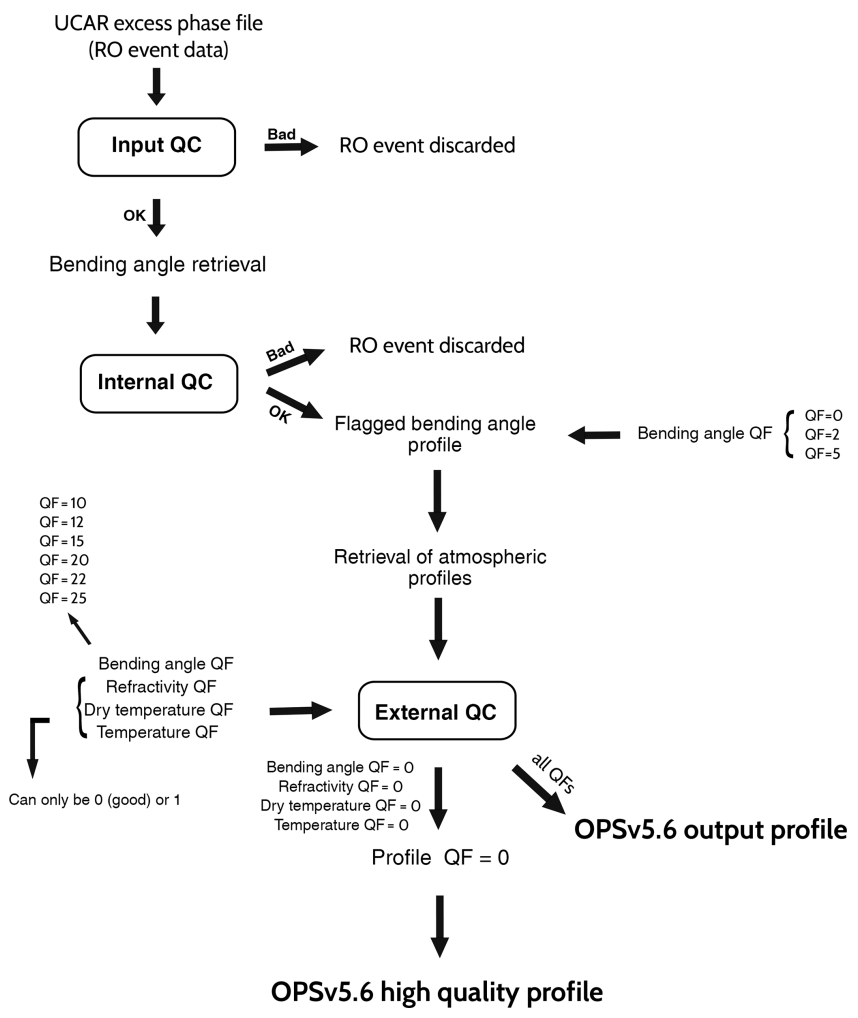

Figure 1. Schematic representation of the quality control approach of the WEGC OPSv5.6 retrieval.

The second step of the quality assessment is the internal QC where the quality of the retrieved ionosphere-corrected bending angle profile is examined. If the quality of the bending angle is not sufficient (i.e. the bending angle noise is greater than $22 \mu \mathrm{rad}$ or the bending angle bias is greater than $10 \mu \mathrm{rad})$ the profile is discarded. Each profile that passes the internal QC gets marked with a bending angle quality flag (QF) according to its quality level and is processed further to atmospheric variables. The bending angle $\mathrm{QF}$ can be set to 0 , 2 , or 5 in the internal $\mathrm{QC}$ where $\mathrm{QF}=0$ marks high bending angle quality. A detailed description of the meaning of the quality flags is given in Table 2 .

Apart from detecting and eliminating profiles with insufficient bending angle quality, the bending angle QF also provides information on the weight of the $\mathrm{RO}$ measurement in the statistically optimized bending angle, being directly related to the observational error magnitude used in statistical optimization. For profiles with bending angle $\mathrm{QF}=0$, the observational error is set to the value of the bending angle noise, or to a constant value ( $4.5 \mu \mathrm{rad}$, empirically determined) for profiles with degrading bending angle quality above $65 \mathrm{~km}$. For profiles with worse bending angle quality $(\mathrm{QF}=2$ or $\mathrm{QF}=5$ ), the use of a larger amount of background information is required. The observational error is therefore set 
Table 2. Quality flags (QFs) defined within the WEGC OPSv5.6 data processing.

\begin{tabular}{|c|c|c|c|}
\hline Variable & Flag & Type & Meaning \\
\hline \multirow[t]{9}{*}{ Bending angle } & $\mathrm{QF}=0$ & internal QC & All checks passed. Bending angle retrieval results are of high quality. \\
\hline & $\mathrm{QF}=2$ & internal QC & $\begin{array}{l}\text { Bending angle noise could not be calculated from bending angle profile. A large } \\
\text { observational error }(22 \mu \mathrm{rad}) \text { is used in the retrieval. }\end{array}$ \\
\hline & $\mathrm{QF}=5$ & internal QC & $\begin{array}{l}\text { Negative bending angles below } 50 \mathrm{~km} \text {. A large observational error }(22 \mu \mathrm{rad}) \text { is } \\
\text { used in the retrieval. Only non-optimized bending angle profiles should be used. }\end{array}$ \\
\hline & $\mathrm{QF}=10$ & external QC & $\begin{array}{l}\text { If internal } \mathrm{QF}=0 \text { but the relative difference between the retrieved non- } \\
\text { optimized bending angle profile and the co-located ECMWF analysis bending } \\
\text { angle profile is greater than } 20 \% \text { somewhere between } 10 \text { and } 35 \mathrm{~km} \text {. }\end{array}$ \\
\hline & $\mathrm{QF}=12$ & external QC & $\begin{array}{l}\text { If internal } \mathrm{QF}=2 \text { and relative difference to co-located ECMWF exceeds limit } \\
(\text { see } \mathrm{QF}=10) \text {. }\end{array}$ \\
\hline & $\mathrm{QF}=15$ & external QC & $\begin{array}{l}\text { If internal } \mathrm{QF}=5 \text { and relative difference to co-located ECMWF exceeds limit } \\
(\text { see } \mathrm{QF}=10)\end{array}$ \\
\hline & $\mathrm{QF}=20$ & external QC & $\begin{array}{l}\text { Retrieved bending angle profile somewhere contains values outside of }-1 \mathrm{mrad} \\
\text { and } 10 \mathrm{rad} \text {. }\end{array}$ \\
\hline & $\mathrm{QF}=22$ & external QC & $\begin{array}{l}\text { If internal } \mathrm{QF}=2 \text { and bending angle profile contains values outside defined } \\
\text { range ( } \text { see } \mathrm{QF}=20 \text { ). }\end{array}$ \\
\hline & $\mathrm{QF}=25$ & external QC & $\begin{array}{l}\text { If internal } \mathrm{QF}=5 \text { and bending angle profile contains values outside defined } \\
\text { range (see } \mathrm{QF}=20 \text { ). }\end{array}$ \\
\hline Refractivity & $\mathrm{QF}=0,1$ & external QC & $\begin{array}{l}\text { If the relative difference between retrieved RO refractivity profile and the co- } \\
\text { located ECMWF analysis refractivity profile is greater than } 10 \% \text { somewhere } \\
\text { between } 5 \text { and } 35 \mathrm{~km}, \mathrm{QF} \text { is set to } 1 \text {. Else, QF is } 0 \text {. }\end{array}$ \\
\hline $\begin{array}{l}\text { Dry } \\
\text { temperature }\end{array}$ & $\mathrm{QF}=0,1$ & external QC & $\begin{array}{l}\text { If the difference between the retrieved RO dry temperature profile and the co- } \\
\text { located ECMWF analysis dry temperature profile is greater than } 20 \mathrm{~K} \text { some- } \\
\text { where between } 8 \text { and } 25 \mathrm{~km}, \mathrm{QF} \text { is set to } 1 \text {. Else, QF is } 0 \text {. }\end{array}$ \\
\hline Temperature & $\mathrm{QF}=0,1$ & external QC & $\begin{array}{l}\text { If the difference between the retrieved RO physical temperature profile and the } \\
\text { co-located ECMWF analysis physical temperature profile is greater than } 20 \mathrm{~K} \\
\text { somewhere between } 8 \text { and } 25 \mathrm{~km}, \mathrm{QF} \text { is set to } 1 \text {. Else, QF is } 0 \text {. }\end{array}$ \\
\hline Profile & $\mathrm{QF}=0,1$ & $\begin{array}{l}\text { external QC/ } \\
\text { internal QC }\end{array}$ & $\begin{array}{l}\text { Profile QF defines the high-quality profiles. If the QFs of each checked variable } \\
\text { is } 0 \text {, profile QF is set to } 0 \text {, else to } 1 \text {. }\end{array}$ \\
\hline
\end{tabular}

to a larger value ( $22 \mu \mathrm{rad})$, leading to more background information and less observational information in the retrieved variables.

External QC is the third step in the OPSv5.6 QC. It is conducted after finishing the retrieval of all atmospheric parameters. In this step the plausibility of the retrieved atmospheric profiles of bending angle, refractivity, dry temperature, and temperature is examined by comparing them to co-located ECMWF analysis profiles. In this stage of the QC, profiles are not discarded but flagged with a $\mathrm{QF}$ that marks them as bad quality $(\mathrm{QF}=1)$ if the deviations exceed a certain limit (see Table 2). In the case of the bending angle, a QF has already been set in the internal QC.

If the external QC fails for the bending angle, the bending angle QF is updated and, depending on the result of the internal QC, the new QF can be 10, 12, 15, 20, 22, or 25 (see Table 2 for details), where the second digit indicates the internal QC and the first digit indicates the external QC. As an example, $\mathrm{QF}=25$ means that the internal $\mathrm{QF}=5$ (negative bending angles below $50 \mathrm{~km}$ ) and the external $\mathrm{QF}=20$ (retrieved bending angle profile somewhere contains values outside of $-1 \mathrm{mrad}$ and $10 \mathrm{rad}$ ). In addition to the individual QFs of the retrieved atmospheric parameters, the so-called profile QF is defined. This QF is only 0 if all QFs are 0 .

An OPSv5.6 output profile is hence always flagged with five quality flags: bending angle QF, refractivity QF, dry temperature QF, temperature QF, and an overall profile QF. Only if the profile $\mathrm{QF}=0$, the profile denotes an OPSv5.6 highquality profile and is recommended to be used for all general applications. However, depending on the user's needs, profiles with other QFs can also be of particular interest.

\section{Quality aspects of the individual satellites}

Knowledge of the differences in quality of the various satellite data is essential, especially if data from several missions are combined into a multi-satellite record. Figures 2 and 3 illustrate the quality of RO data from different missions as identified by OPSv5.6. Figure 4 illustrates the spatial distribution of RO event locations of all processed RO mis- 

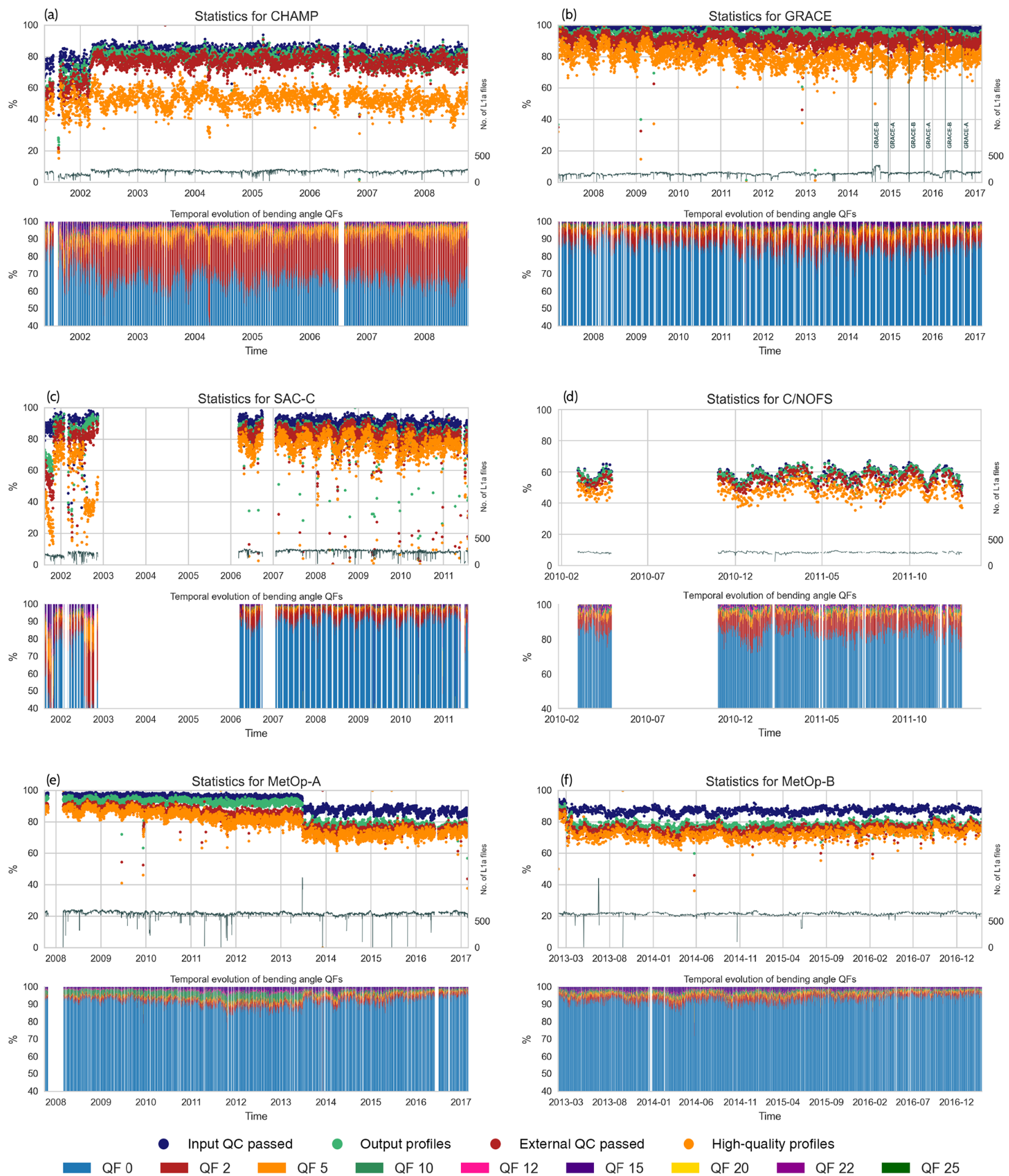

Figure 2. Temporal evolution of daily percentage of profiles (relative to total number of input data) passing the various QC steps for (a) CHAMP, (b) GRACE, (c) SAC-C, (d) C/NOFS, (e) MetOp-A and (f) MetOp-B (upper panels). Upper subpanels of (a)-(f) show the number of profiles passing the input QC (blue dots); the number of bending angle profiles passing internal QC, which equals the number of output profiles (green dots); the number of profiles that are within the defined limits in the external QC (bending angle QF is 0, 2, or 5, and all atmospheric QF are 0) (red dots); and the daily percentage of high-quality OPSv5.6 profiles (orange dots). Daily percentage of flagged profiles relative to the number of OPSv5.6 output profiles is shown separately for each bending angle QF in the lower subpanels. 

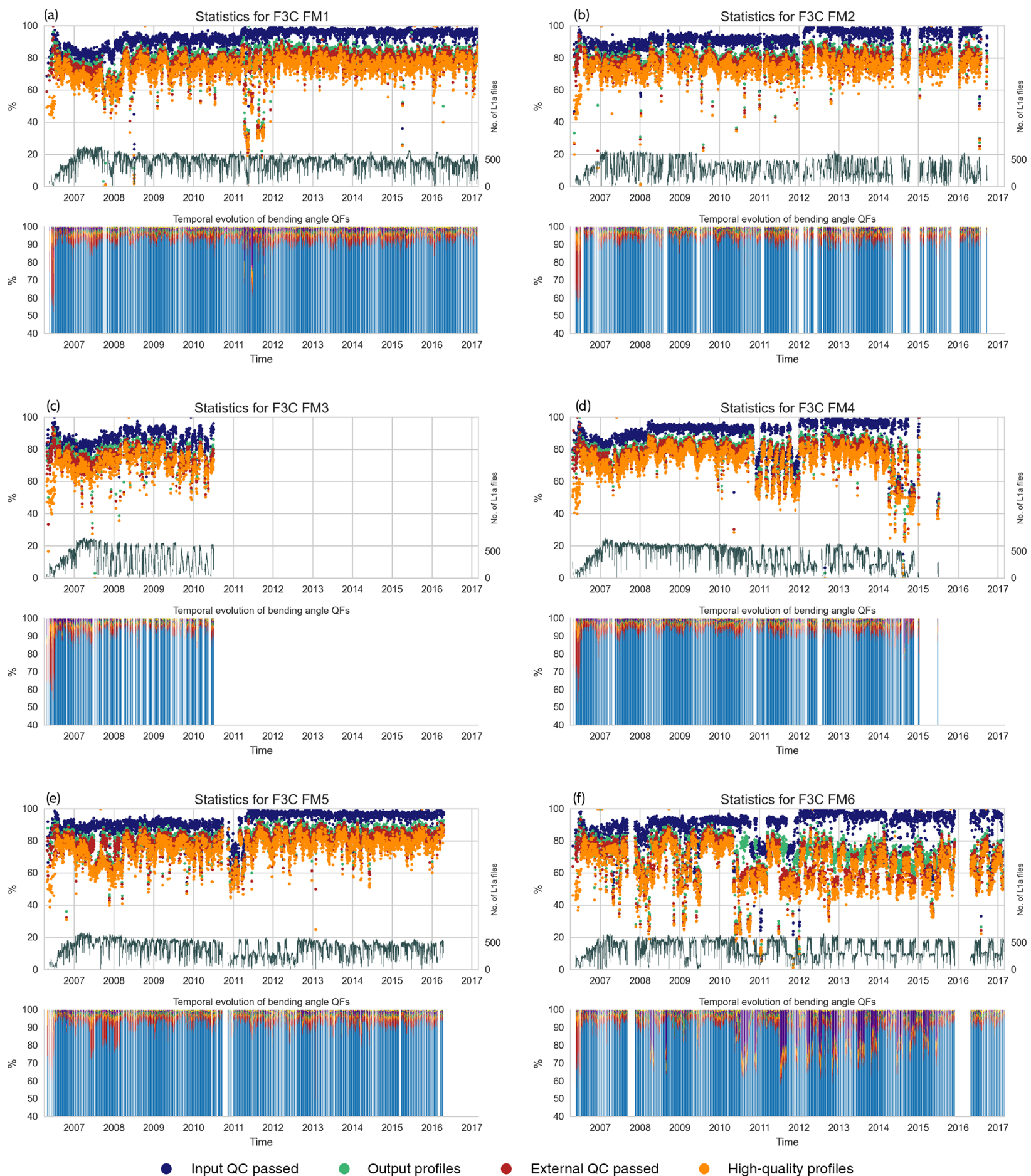

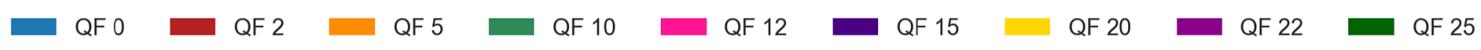

Figure 3. Temporal evolution of daily percentage of profiles (relative to total number of input data) passing the various QC steps for the six F3C satellites, (a) FM1, (b) FM2, (c) FM3, (d) FM4, (e) FM5, and (f) FM6. Upper subpanels of (a)-(f) show the number of profiles passing the input QC (blue dots); the number of bending angle profiles passing internal QC, which equals the number of output profiles (green dots); the number of profiles that are within the defined limits in the external QC (bending angle QF is 0,2, or 5, and all atmospheric QF are 0) (red dots); and the daily percentage of high-quality OPSv5.6 profiles (orange dots). Daily percentage of flagged profiles relative to the number of OPSv5.6 output profiles is shown separately for each bending angle QF in the lower subpanels. 

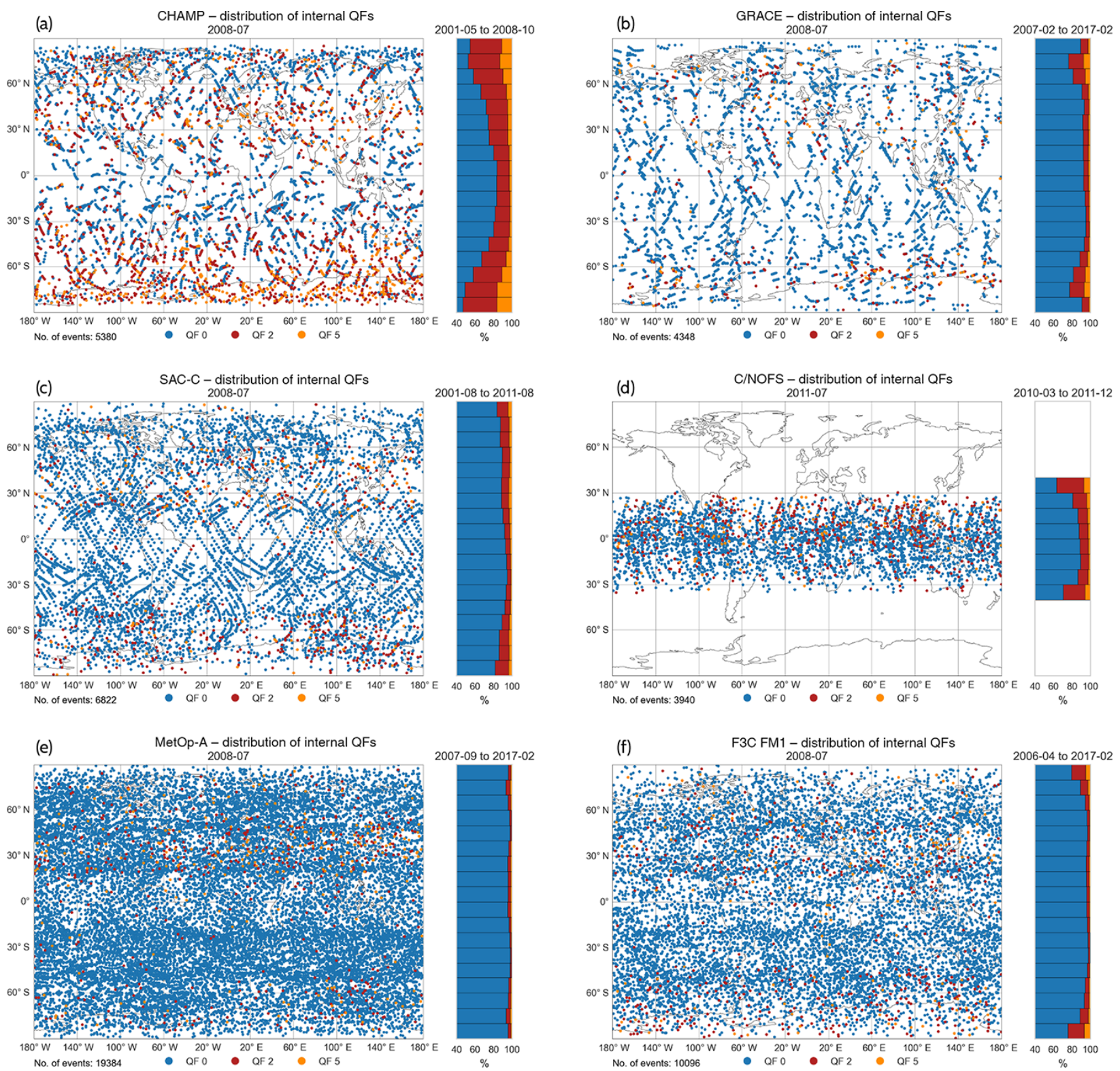

Figure 4. Spatial distribution of the RO events with bending angle QF $=0$, 2, or 5 for the satellites (a) CHAMP, (b) GRACE, (c) SAC-C, (d) C/NOFS, (e) MetOp-A, and (f) F3C FM1, showing the geographical coverage for one exemplary month (left subpanels) and the latitudinal distribution over the complete available time range per satellite (right subpanels).

sions with their respective internal bending angle QF for one specific month as well as the latitudinal distribution of the internal bending angle QFs over the complete time range per satellite. Figure 5 comprises the information about the number of high-quality profiles on a monthly timescale for all satellites processed within the OPSv5.6 retrieval. In Table 3 an overview of the number of provided UCAR/CDAAC phase delays, the OPSv5.6 output profiles, and the highquality profiles per satellite is given.
In the following, we discuss commonalities and differences between the satellites before going into the details of satellite-specific features.

\subsection{General features}

The upper panels of Figs. 2 and 3 show the temporal evolution of the relative number of profiles passing various QC steps. The daily percentage is calculated relative to the total number of input files. In general, the input $\mathrm{QC}$ and the internal QC have the strongest impact on the number of highquality profiles while the influence of the external QC is 


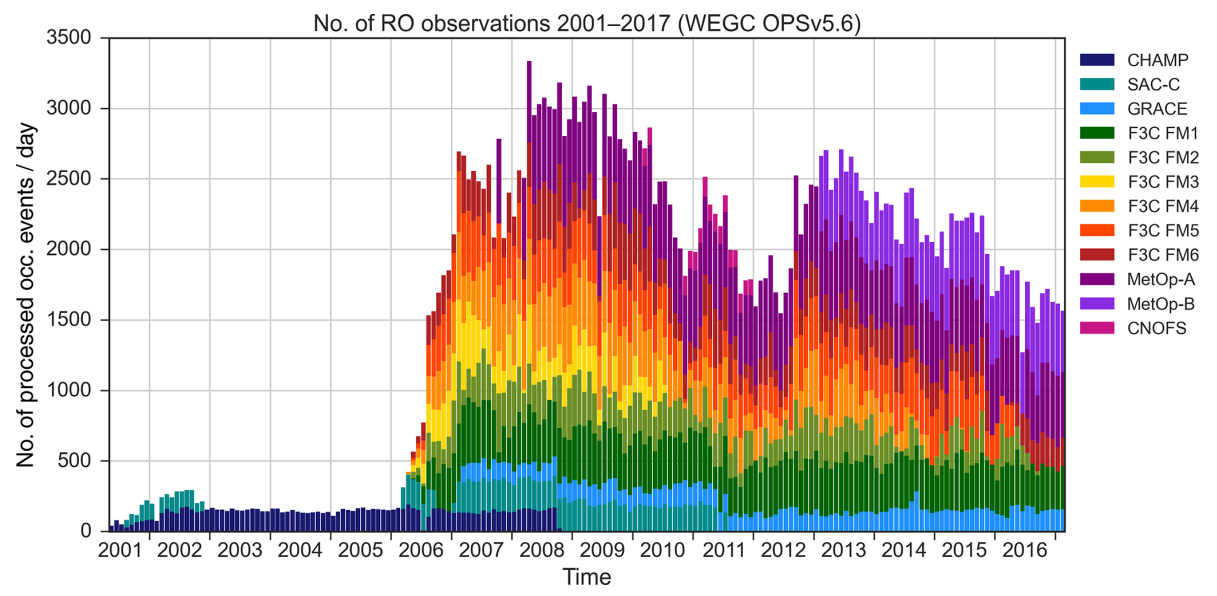

Figure 5. Daily number of high-quality OPSv5.6 profiles for different satellites (different colours) as a function of time from 2001 to 2017.

Table 3. Overview of daily average number of available UCAR/CDAAC excess phase files (one file per RO event) and the corresponding percentages of retrieved OPSv5.6 output profiles and high-quality profiles.

\begin{tabular}{lccc}
\hline Mission & $\begin{array}{c}\text { Average no. of } \\
\text { UCAR/CDAAC } \\
\text { excess phase } \\
\text { files }\left(\text { day }^{-1}\right)\end{array}$ & $\begin{array}{c}\text { OPSv5.6 } \\
\text { output } \\
\text { profiles } \\
{[\%] \text { (all QFs) }}\end{array}$ & $\begin{array}{c}\text { OPSv5.6 } \\
\text { high-quality } \\
\text { profiles [\%] } \\
(\mathrm{QF}=0)\end{array}$ \\
\hline CHAMP & 206 & $78 \%$ & $52 \%$ \\
GRACE & 197 & $94 \%$ & $80 \%$ \\
SAC-C & 245 & $83 \%$ & $71 \%$ \\
C/NOFS & 250 & $57 \%$ & $48 \%$ \\
MetOp-A & 650 & $87 \%$ & $80 \%$ \\
MetOp-B & 643 & $78 \%$ & $72 \%$ \\
F3C FM1 & 467 & $79 \%$ & $72 \%$ \\
F3C FM2 & 353 & $80 \%$ & $74 \%$ \\
F3C FM3 & 407 & $77 \%$ & $70 \%$ \\
F3C FM4 & 429 & $78 \%$ & $72 \%$ \\
F3C FM5 & 409 & $82 \%$ & $75 \%$ \\
F3C FM6 & 393 & $71 \%$ & $62 \%$ \\
\hline
\end{tabular}

comparatively low. The majority of all OPSv5.6 output profiles is flagged with $\mathrm{QF}=0$ as found in the lower panels of Figs. 2 and 3. However, some irregularities and satellitespecific characteristics can be detected. The percentage of high-quality profiles differs considerably among the satellites, which clearly points to the differences in individual satellite data quality. Besides that, data quality can also vary significantly over time.

The characteristics in the spatial event distribution, as shown in Fig. 4, reflect the different orbit designs of the receiving LEO satellites. The left subpanels show the horizontal distribution of the internal QFs for one exemplary month (July 2008 and July 2011, respectively), indicating some seasonal effect at high latitudes. The right subpanels depict the mean latitudinal distribution, revealing an equal distribution for both the Northern and Southern hemispheres for all satellites.

Figure 5 reveals the vast increase in OPSv5.6 profiles in mid-2006, when RO data provision of the F3C mission was started. A decline in the number of profiles can be observed in the last years, as some of the used RO missions already exceeded their designated lifetimes.

The capability to track setting as well as rising signals is reflected in the number of provided measurements, as obtainable from Table 3. The lowest number can be found for CHAMP and GRACE, for which only setting measurements are available. The F3C satellites and MetOp, which are capable of tracking both kind of signals, provide two (F3C) or even three times (MetOp) as many measurements. The number of output profiles varies between $57 \%$ (C/NOFS) and a maximum of $94 \%$ for GRACE. The majority of the missions obtain around $70 \%$ of high-quality data.

\subsection{CHAMP}

Of all CHAMP data, $18 \%$ are rejected in the OPSv5.6 input QC and only $52 \%$ of all UCAR/CDAAC input data yield high-quality output profiles (Fig. 2a). Compared to the other satellites, this number is quite low. The daily percentage of profiles passing the different QC steps is constant over time, except at the beginning of the time series. A firmware update in March 2002 slightly increased the number of high-quality profiles. The difference between the total number of OPSv5.6 output profiles and the OPSv5.6 high-quality profiles can mainly be attributed to the high number of profiles flagged with $\mathrm{QF}=2$, primarily induced by negative bending angles between 50 and $55 \mathrm{~km}$. A semi-annual cycle is observable in the temporal evolution of high-quality profiles because of the systematic rejection of very cold profiles (Schwarz, 2013).

The CHAMP orbit has an inclination of $87^{\circ}$, which yields quite a homogeneous global distribution, with slightly fewer measurements in the tropics; see Fig. 4a. The number of pro- 
files with $\mathrm{QF}=2$ and $\mathrm{QF}=5$ is greatest between 60 and $90^{\circ} \mathrm{S}$ in July 2008 (Antarctic winter). Averaged over the complete time period (right panel of Fig. 4a) profiles with $\mathrm{QF}=2$ and $\mathrm{QF}=5$ are equally distributed above both poles. This can be understood as follows: between 50 and $55 \mathrm{~km}$ the absolute atmospheric bending angle is small. Due to the comparatively high noise of CHAMP data it can happen that some values in the bending angle profile are negative. This more likely occurs in very cold regions, where the absolute bending angle values are particularly small. This effect is visible for all satellites; however it is strongest for CHAMP.

\subsection{GRACE}

The data quality of the GRACE mission is very good. There is almost no loss due to input QC and $80 \%$ of all input data yield high-quality profiles (Fig. 2b). Furthermore data quality is constant over time: only a slight decline in high-quality profiles is visible, which might be attributable to a degrading instrument performance after exceeding its planned lifetime. There is no apparent change in data quality between the twin satellites, as both are equipped with the same receiver (time periods where RO measurements where taken by GRACE-B instead of GRACE-A are marked in Fig. 2b).

The number of provided UCAR/CDAAC phase delay files is significantly lower for GRACE than for other satellites (Table 3): Around 200 events per day, in contrast to, e.g. the average number of around 400 events per day for F3C FM5. Since the input QC rejects only very few of these events, measurements of lower data quality are presumably rejected already at a previous processing step.

Due to its polar orbit ( $89^{\circ}$ inclined) the occultation event locations are evenly distributed over the globe (Fig. 4b). The same spatial pattern of QF distribution (i.e. high number of $\mathrm{QF}=2$ and $\mathrm{QF}=5$ profiles at high latitudes due to the rejection of very cold profiles) can be observed for GRACE as for CHAMP but with reduced strength.

\subsection{SAC-C}

The number of high-quality profiles varies strongly in the beginning of the mission, but from 2006 onwards the quality remains constant with time with an average number of $71 \%$ high-quality profiles (Fig. 2c). From late 2002 on, the newly developed OL tracking mode was tested on SAC-C to enable the tracking of signals in rising occultation. A stable version was then established in March 2006 (Ao et al., 2009). In the testing phase between 2003 and 2006, UCAR/CDAAC does not provide any measurement data.

Data prior to the OL testing phase have been processed with an older UCAR/CDAAC data version (Table 1) and because of the strongly varying data quality during this period we do not recommend using SAC-C data before 2006. Again, the semi-annual cycle of the percentage of high-quality measurements (Fig. 2c) as well as the latitudinal dependency of the QFs (Fig. 4c) induced by the rejection of very cold profiles is visible, similarly to CHAMP and GRACE.

\section{$4.5 \mathrm{C} / \mathrm{NOFS}$}

The C/NOFS mission operated from 2008 to 2015; however UCAR/CDAAC only provides post-processed C/NOFS measurements from 2010 to 2011. More than $40 \%$ of all C/NOFS input data are discarded in the input QC (Fig. 2d), because many events are too short and do not cover the altitude range from 20 to $65 \mathrm{~km}$. However, although there seems to be a problem in the vertical availability of C/NOFS measurements, the majority of the profiles that pass internal QC ( $48 \%$ of all input data) are of high quality (see lower panel of Fig. 2d).

Because of the near-equatorial orbit of C/NOFS (inclination of $13^{\circ}$ ), RO measurements are only available at low latitudes up to $30^{\circ}$ (Fig. 4d). Due to its focus on low latitudes, RO data from the C/NOFS mission can be valuable for studies concerning the tropical region, where the density of RO measurements is generally lower.

\subsection{MetOp}

Compared to the other satellite missions, the number of MetOp RO measurements is significantly higher. Around 600 events per day can be detected, since MetOp is able to take two rising and two setting occultation measurements simultaneously. MetOp-A shows remarkably good and constant data quality, especially until mid-2013. From mid-2013 onwards the number of data passing the input and internal QC diminishes (from around 85 to $75 \%$ ), yielding a total average of $80 \%$ high-quality profiles. A tracking parameter update, which took place in June 2013 on the MetOp-A GRAS receiver (Christian Marquardt/EUMETSAT, personal communication, 2017), is reflected in the statistics of the QC, showing a decline in the number of profiles passing input QC as well as internal QC.

Compared to the other satellites, the external QC has the largest impact for MetOp-A before mid-2013 (Fig. 2e). MetOp-B also shows high data quality (Fig. 2f). A decline in the number of data passing input and internal QC occurs in April 2013, when the tracking parameter update has been applied to MetOp-B. Amongst other things, this update introduced a change in the tracking of the L2 signal for rising occultations: it is now measured from a $15 \mathrm{~km}$ straight-linetangent altitude (about $20 \mathrm{~km}$ impact altitude) upwards only. Since the OPSv5.6 uses the bending angles between 15 and $20 \mathrm{~km}$ to extend the ionosphere correction in the troposphere this update implies that this correction cannot be applied. If the lowermost ray is above $20 \mathrm{~km}$ impact altitude the profile is rejected by the $\mathrm{QC}$ completely.

The temporal evolution of the percentage of high-quality profiles of both MetOp satellites is constant with almost no outliers (Fig. 2e and f). Figure 4e illustrates the global cover- 
age of MetOp-A occultations, with a slightly increased coverage in the midlatitudes, which is attributed to the orbit inclination of $98.7^{\circ}$. Since MetOp-A and MetOp-B are operating in the same orbit, we only show results from MetOp-A in Fig. $4 \mathrm{e}$ as they are representative for both MetOp satellites.

\subsection{FORMOSAT-3/COSMIC}

The six F3C satellites show similar characteristics in data quality throughout their active time periods; see Fig. 3. Distinct increases in input data quality are induced by firmware updates of the GPS receivers, e.g. in August 2006 and in January 2012.

The daily number of measurements varies strongly with time. There are also significantly stronger variations in the temporal evolution of high-quality profiles compared to the other satellites. These variations can mainly be attributed to the internal QC. The semi-annual cycle of the percentage of high-quality profiles mainly stems from the rejection of bending angle profiles with a bending angle noise exceeding $22 \mu \mathrm{rad}$. All satellites also display divergent behaviour in the very beginning of the mission, between April and July 2006 (before the first firmware update took place), where the number of profiles flagged with $\mathrm{QF}=2$ is significantly higher than in the subsequent time period. Strong variations in data quality also appear in 2011, especially for F3C FM4. The time period is much shorter for F3C FM3, as it has been out of operation since August 2010.

Global coverage is also achieved for the $\mathrm{F} 3 \mathrm{C}$ mission (see Fig. 4f for FM1, which is representative for the other F3C satellites), with slightly fewer measurements near the poles and in the tropics.

\section{Towards a combined multi-satellite record}

The unique properties of RO, including high accuracy and long-term stability, can be exploited to create a consistent multi-satellite climate record. To ensure a high-quality and consistent multi-satellite OPSv5.6 RO record, we first inspect the respective bending angle characteristics to identify unusual behaviour that would lead to inconsistencies in the combined data set. We then consider differences in the sampling characteristics of the various missions and analyse deviations from the multi-satellite mean in retrieved temperature time series.

\subsection{Bending angle consistency}

To validate the quality and consistency of OPSv5.6 data, we analyse bending angle bias, standard deviation of the bending angle noise (for brevity just termed "noise" hereafter), and the altitude at which the retrieval to a priori error ratio equals $50 \%$ (zRAER50). All these parameters are defined within the OPSv5.6 retrieval chain (see Sect. 3.1 for how they are estimated) and characterize the quality of the retrieved bend- ing angle. Therefore, they are suitable quantities for validating data consistency, as already shown by Pirscher (2010), Foelsche et al. (2011), and Schwärz et al. (2016).

In Fig. 6a we show the temporal evolution of the daily median bias for all satellites processed within the OPSv5.6 retrieval. For climate applications it is important that the bending angle bias is similar for all satellites and close to zero, which is true for all satellites. The slightly negative values are mainly attributed to residual ionospheric effects (Danzer et al., 2013). No distinct inhomogeneities are visible over time and the mean values vary between $-0.09 \mu \mathrm{rad}$ for SAC$\mathrm{C}$ and $-0.20 \mu \mathrm{rad}$ for $\mathrm{C} / \mathrm{NOFS}$. These slightly different mean values might result from data being available from different time periods.

C/NOFS data, for example, are only available in 2010 and 2011, when solar activity was high, and only cover the lower latitudes, where the total electron content (TEC) is comparatively high. High solar activity causes a higher level of ionization in the Earth's upper atmosphere, which again affects the quality of RO measurements (i.e. a larger ionospheric residual and therefore a larger bending angle bias). This has been empirically shown by Schreiner et al. (2011) and Danzer et al. (2013) and underpinned by end-to-end simulations including atmospheric and ionospheric models by Liu et al. (2015).

The temporal evolution of the daily median bending angle noise is depicted in Fig. 6b. The bending angle noise, which mainly reflects the quality of the GPS receiver and the residual clock errors, is largest for CHAMP with $4.00 \mu \mathrm{rad}$. The BlackJack receiver mounted on CHAMP is a receiver of the first generation (Sect. 2), which explains the comparatively high noise for CHAMP. Bending angle noise is significantly lower $(2.47 \mu \mathrm{rad})$ for GRACE, which also utilizes a BlackJack receiver but an advanced version. In addition, zero differencing can be applied to account for the receiver clock error due to ultra-stable oscillators used in the GRACE mission, which also leads to less noisy data (Beyerle et al., 2005). We assume that zero differencing has been first applied to GRACE in the UCAR/CDAAC 2014.2760 data version, as the noise value becomes smaller in the time period after April 2014.

The smallest bending angle noise is found for the two MetOp satellites, with $0.90 \mu \mathrm{rad}$ for MetOp-A and $0.95 \mu \mathrm{rad}$ for MetOp-B, which reflects the excellent quality of the MetOp/GRAS receiver. SAC-C and all six F3C satellites reveal large temporal variability of noise at the beginning of their mission lifetimes. Due to these large fluctuations, which match the results shown in Sect. 4, data from these time periods (August 2001 to November 2002 for SAC-C and April 2006 to July 2006 for F3C) are not included in OPSv5.6 multi-satellite climatologies; in the subsequent time periods the noise amounts to about $2.5 \mu \mathrm{rad}$ including single differencing for $\mathrm{F} 3 \mathrm{C}$ and around $3 \mu \mathrm{rad}$ for SAC-C.

Figure 7 shows that zRAER50 for MetOp is at a considerably higher impact altitude than for all other satellites. The 

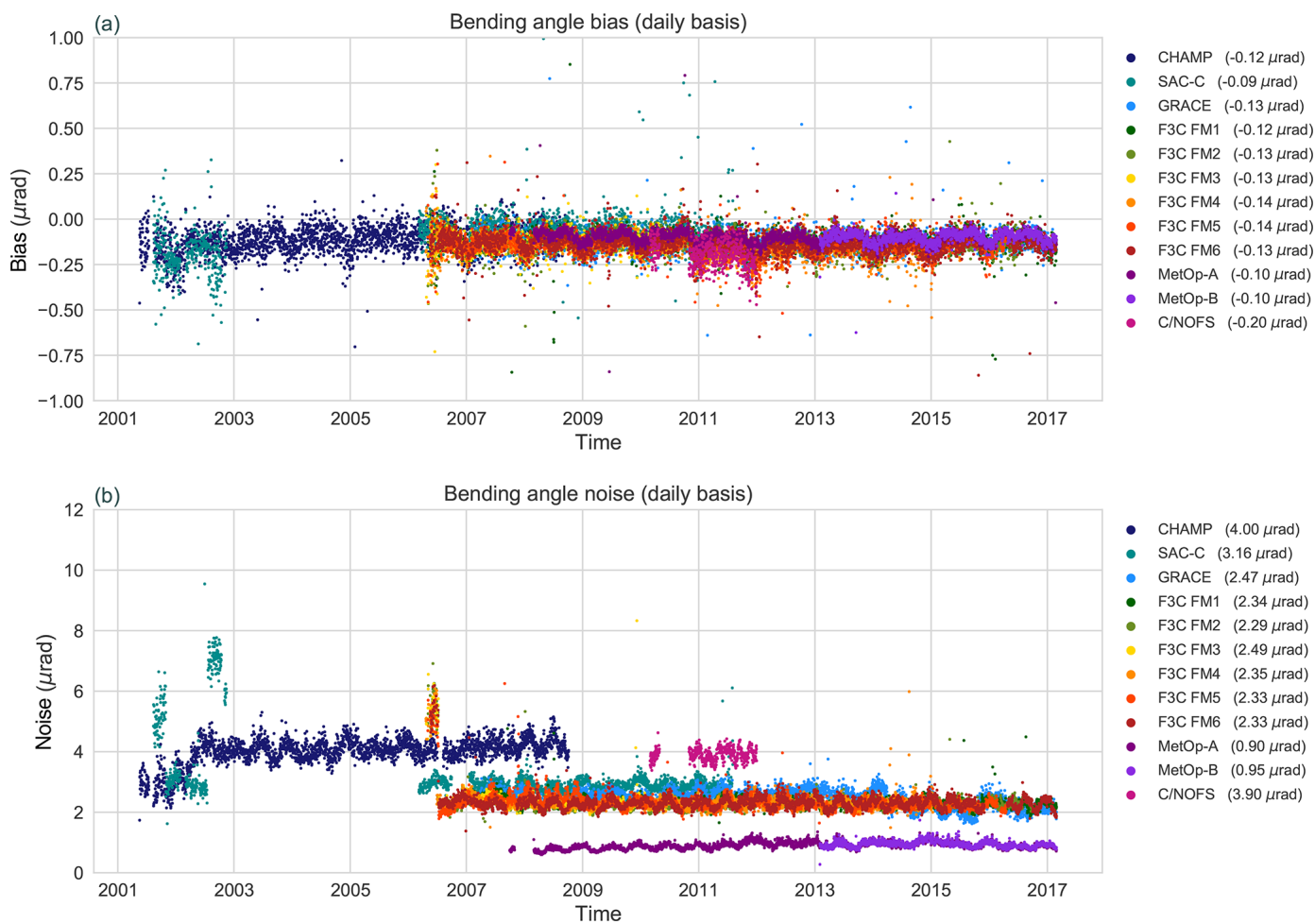

Figure 6. Temporal evolution of daily median bending angle bias (a) and bending angle noise standard deviation (b) for all RO missions used in OPSv5.6. Total mean of bending angle bias and noise is shown as a value in parentheses in the respective legend. Only high-quality profiles are used in these statistics.

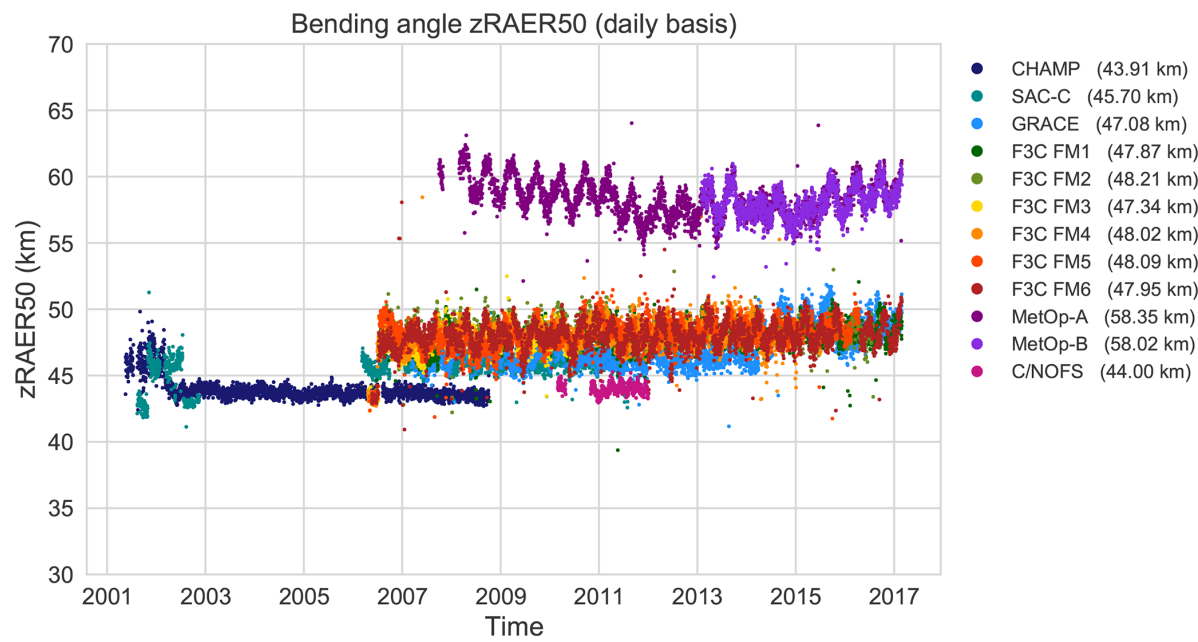

Figure 7. Temporal evolution of daily mean bending angle zRAER50 for all RO missions processed in OPSv5.6. The total mean of zRAER50 is shown as a value in parentheses in the legend. Only high-quality profiles are used in these statistics.

mean zRAER50 is similar for F3C and GRACE, whereas CHAMP shows zRAER50 values at the lowest impact altitude. The assumed change to zero differencing for GRACE in the newer data version (2014.2760) is reflected in the increased zRAER50 value in April 2014. The zRAER50 parameter (Sect. 3.1) is strongly influenced by the quality of the satellite's receiver. Because of the high quality of the
MetOp/GRAS receiver, the influence of the ECMWF background field on the MetOp observations is far smaller than for any other satellite at the same altitude level, confirming early theoretical/simulation studies such as by Rieder and Kirchengast (2001) and Steiner and Kirchengast (2005).

Figure 8 shows the impact of the statistical optimization on the monthly mean bending angle profiles of F3C FM2 

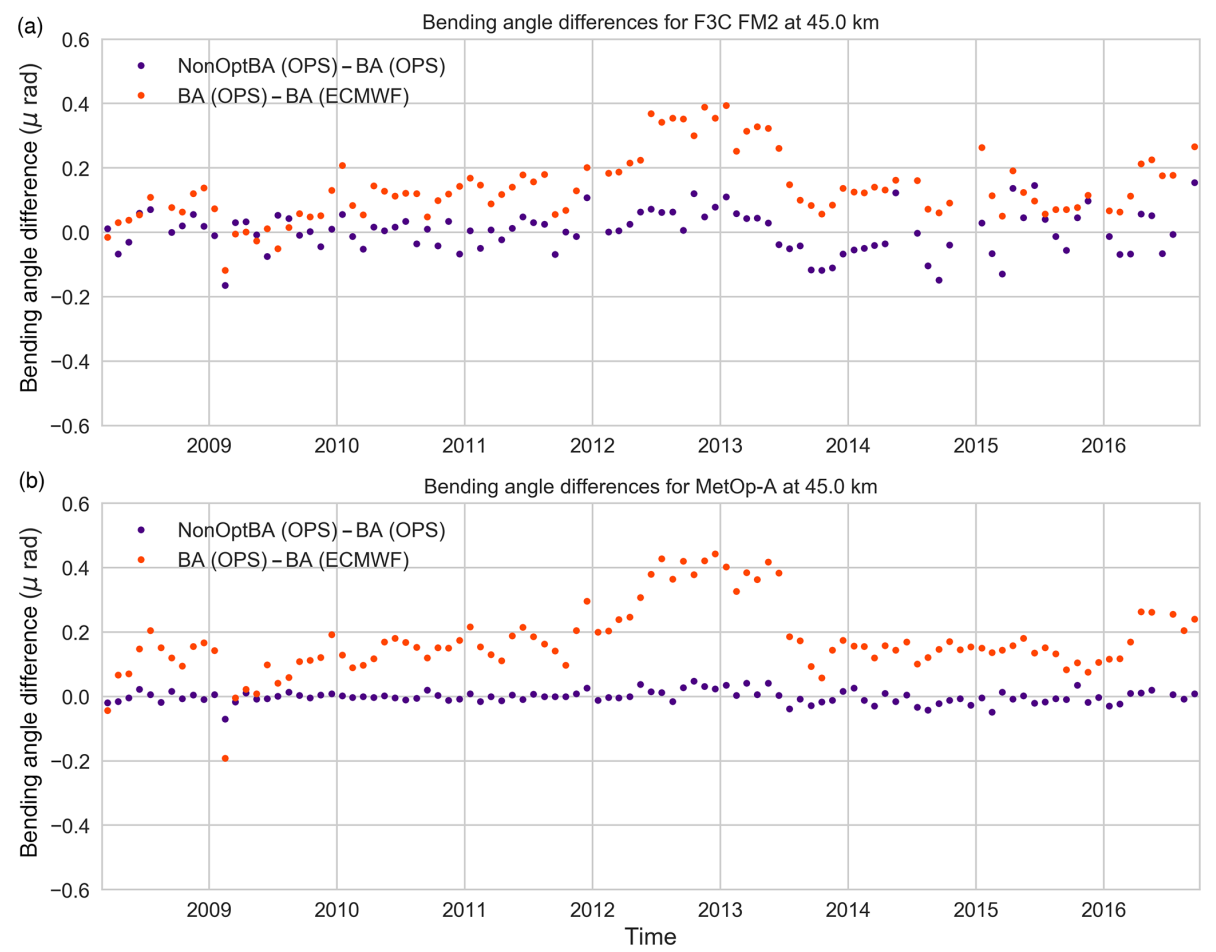

Figure 8. Monthly averaged differences between non-optimized (NonOptBA) and statistically optimized OPSv5.6 bending angle (BA) (violet dots) as well as between statistically optimized OPSv5.6 bending angle and co-located ECMWF bending angle (orange dots) shown for F3C FM2 (a) and for MetOp-A (b) at an impact altitude of $45 \mathrm{~km}$.

and MetOp-A at $45 \mathrm{~km}$ impact altitude, where the RAER is already at around $50 \%$ for F3C FM2 but still significantly lower for MetOp. Differences between the non-optimized bending angle and the statistically optimized bending angle for both satellites fluctuate around zero (violet dots). However F3C FM2 shows larger variations than MetOp. The influence of background information on statistically optimized F3C FM2 bending angles can best be seen during significant changes in the ECMWF system (e.g. mid-2012 and mid-2013). Since ECMWF data are used as background information in the statistical optimization (see Sect. 3.1), the difference between non-optimized and statistically optimized bending angle shows some (small) jumps during these time periods.

In comparison, such changes in ECMWF are less visible in the MetOp time series. From this we can conclude that due to the high quality of the Metop/GRAS receiver, the highaltitude initialization (and with that, ECMWF model system changes) has less of an impact on retrieved MetOp profiles compared to other missions. This has to be kept in mind when generating a combined multi-satellite record from all RO missions.

\subsection{Monthly mean multi-satellite climatologies}

When combining data from different satellite missions to a global multi-satellite record, not only do the quality and consistency of the retrieved atmospheric profiles have to be taken into account, but so do the differences in spatial and temporal sampling. The error due to discrete sampling (sampling error) can be estimated from the difference between the averaged co-located ECMWF analysis profiles and the averaged full ECMWF field (Foelsche et al., 2008; Pirscher et al., 2010). In order to account for the sampling error, it is subtracted from the climatology (e.g. Foelsche et al., 2011; Steiner et al., 2011), leaving a small residual sampling error (for detailed information see Scherllin-Pirscher et al., 2011a).

The impact of the sampling error correction is clearly visible in Fig. 9. These monthly mean global mean dry temperature differences are calculated for each satellite relative to the multi-satellite mean between 8 and $25 \mathrm{~km}$ height following Foelsche et al. (2011) and Steiner et al. (2011). If no sampling error correction is applied (Fig. 9a), deviations mainly vary between $0.5 \mathrm{~K}$ with large outliers occurring in mid-2011 (out of plot scale). These outliers stem from large deviations of C/NOFS, which only provides data for the tropics. Not considering these special spatial sampling characteristics leads to a bias in the global mean. With the sampling error correction applied (Fig. 9b), deviations are below $0.1 \mathrm{~K}$ for all satellites in the 8 to $25 \mathrm{~km}$ height range where $\mathrm{RO}$ is of the highest quality. 

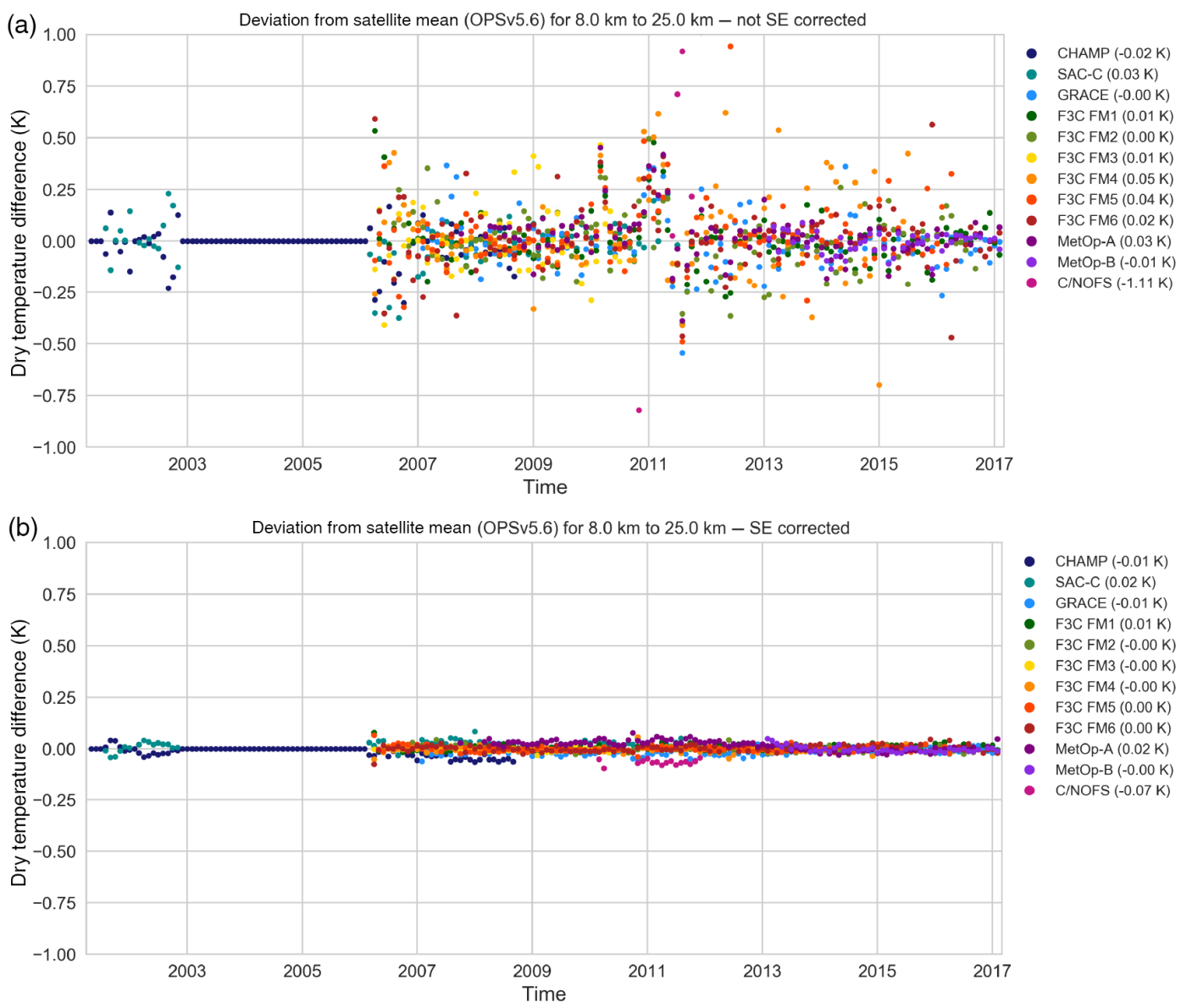

Figure 9. Deviations of individual satellites from the multi-satellite mean for monthly mean dry temperature in altitude layer 8-25 km, without sampling error (SE) correction (a) and with SE correction applied (b). The satellite mean is calculated from all missions available for the respective month (note that before May 2006 only CHAMP and SAC-C delivered data).

At higher altitudes, between 25 and $35 \mathrm{~km}$, MetOp-A reveals a distinctively different behaviour from the other satellites before mid-2013 but a consistent one after that (Fig. 10). This change in the characteristics of MetOp dry temperature deviations coincides precisely with an ECMWF model system change (cycle 38r2), where, among other changes, the number of vertical levels was increased in the model.

Several other ECMWF model system changes can be identified in the deviations from each satellite to the ECMWF analysis field in this altitude range; see Fig. 10. We find that the improvements of the model are reflected in decreasing deviations of the RO data from ECMWF after 2013. This is specifically evident for MetOp, which is generally less ECMWF-affected in this altitude range than the other satellites and which shows the largest decrease in deviation from ECMWF. With the increase in quality of the ECMWF model system, the analysis approaches the high-quality atmospheric information provided by MetOp, resulting in better quality of the other, more ECMWF-affected, satellites.

At lower altitudes up to $25 \mathrm{~km}$ the impact of the highaltitude initialization on the RO temperature is small. Con- sequently different RO missions can be readily combined into a multi-satellite data set (see Fig. 9 and Steiner et al., 2011; Foelsche et al., 2011). Above $25 \mathrm{~km}$, the RO temperature record is increasingly influenced by the characteristics of the initialization, with the amount of impact depending on the receiver quality. This effect is most pronounced for temperature, since the hydrostatic integration in the retrieval step from refractivity (density) to pressure leads to a downward propagation of high-altitude initalization errors, propagating further into temperature. High consistency in refractivity can be achieved up to altitudes of about $30 \mathrm{~km}$ (Foelsche et al., 2011).

\section{Summary and conclusions}

In this study, we performed a quality analysis of the individual satellite data sets comprising the latest version of the Wegener Center multi-satellite GPS RO record WEGC OPSv5.6. We described the QC procedure applied in the OPSv5.6 retrieval and included a detailed analysis of the 

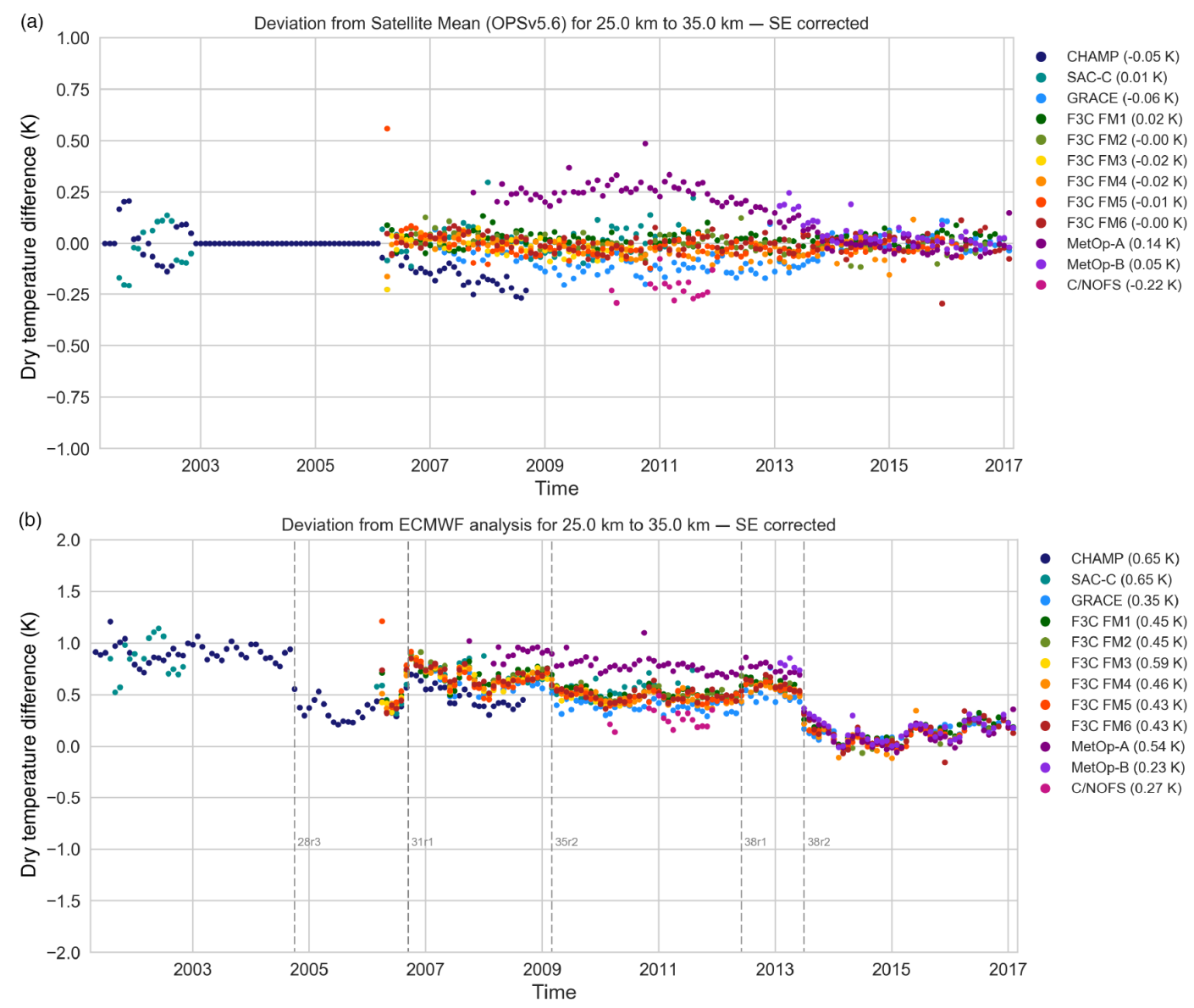

Figure 10. Deviations of individual satellites from the multi-satellite mean (a) and from the ECMWF analysis (b) for monthly mean dry temperature in the altitude layer $25-35 \mathrm{~km}$. Points in time (vertical dashed line) mark important ECMWF model system changes (b).

impact of the various QC steps on each individual satellite data set for the missions CHAMP, GRACE, SAC-C, C/NOFS, MetOp, and FORMOSAT-3/COSMIC. A rigorous QC is key for establishing a combined multi-satellite record with known properties and shall facilitate proper application of the WEGC OPSv5.6 record.

From this analysis, we conclude that for CHAMP our bending angle quality control passes a less than average number of events as high-quality profiles compared to the other satellites. The six F3C satellites have a comparable, high bending angle quality with quite large day-to-day variations and some satellite-specific irregularities. GRACE and especially the two MetOp satellites show the highest-quality profiles; however the MetOp time series reflects relevant changes in the receiver software. The improvement of the receiver quality with time, from the older BlackJack receivers to the modified BlackJack receiver on GRACE and the GRAS receiver on MetOp, is evident in our analysis.

As the signal-to-noise ratio in the RO observations gets worse with increasing altitude, the observations are merged with background information at high altitudes in the bending angle retrieval. The impact of the background field is strongly dependent on the quality of the receiver and increases with decreasing receiver quality. To establish a homogeneous long-term RO climate record it is thus essential to track the quality and influence of the background field to understand the height-dependent characteristics.

In the OPSv5.6 retrieval ECMWF short-term forecasts are used as background. At higher-altitude levels the influence of the background field increases, and with that certain ECMWF model changes are reflected in the OPSv5.6 retrieval results. In the RO retrieval chain this impact propagates further downwards for each retrieved parameter. We conclude that the OPSv5.6 multi-satellite refractivity/temperature record is only marginally influenced by the ECMWF model up to about 30/25 km and higher for MetOp due to its excellent receiver quality.

The WEGC OPSv5.6 record provides a valuable observational record for atmospheric analysis and climate monitoring. Based on the knowledge from our careful quality control we find that high-quality temperature data from different satellites are highly consistent between 8 and $25 \mathrm{~km}$, with deviations from the multi-satellite mean of less than $0.1 \mathrm{~K}$. Above, the quality of individual satellite records depends on 
receiver quality and the amount of background information that is entered. The MetOp record provides high-quality observational information to higher altitudes which is reflected in a larger divergence from the multi-satellite mean between 25 and $35 \mathrm{~km}$. Improvements in the quality of the background field in 2013 led to much smaller deviations of less than $0.2 \mathrm{~K}$. These findings have to be taken into account when using the WEGC OPSv5.6 RO record above about 25 to $35 \mathrm{~km}$ for climate trend applications.

This work aids the maturation of the RO record with respect to knowledge of data quality and its description (Bates and Privette, 2012) and helps to meet the stringent requirements as defined by the Global Climate Observing System (GCOS, 2010a, b, 2011) for the generation of a climate data record of essential climate variables.

Data availability. The data set is currently available on request from the authors and will be made publicly available soon via an online resource.

The RO excess phase and orbit data from UCAR/CDAAC are available at http://cdaac-www.cosmic.ucar.edu/ (UCAR/CDAAC, 2017). The analysis and forecast data from ECMWF are available at http://www.ecmwf.int/en/forecasts/datasets (ECMWF, 2017).

Competing interests. The authors declare that they have no conflict of interest.

Special issue statement. This article is part of the special issue "Observing Atmosphere and Climate with Occultation Techniques - Results from the OPAC-IROWG 2016 Workshop". It is a result of the International Workshop on Occultations for Probing Atmosphere and Climate, Leibnitz, Austria, 8-14 September 2016.

Acknowledgements. We are grateful to UCAR/CDAAC (Boulder, $\mathrm{CO}$, USA) for the provision of its RO excess phase and orbit data and ECMWF (Reading, UK) for providing access to analysis and forecast data. This work was funded by the Austrian Science Fund (FWF) under grant P27724-NBL (VERTICLIM) as well as by the FFG-ALR projects OPSCLIMTRACE (ASAP-9 844395) and OPSCLIMVALUE (ASAP-10 848013).

Edited by: Axel von Engeln

Reviewed by: two anonymous referees

\section{References}

Anthes, R. A.: Exploring Earth's atmosphere with radio occultation: contributions to weather, climate and space weather, Atmos. Meas. Tech., 4, 1077-1103, https://doi.org/10.5194/amt-4-10772011, 2011.

Anthes, R. A., Bernhardt, P. A., Chen, Y., Cucurull, L., Dymond, K. F., Ector, D., Healy, S. B., Ho, S.-P., Hunt, D. C., Kuo, Y.-
H., Liu, H., Manning, K., McCormick, C., Meehan, T. K., Randel, W. J., Rocken, C., Schreiner, W. S., Sokolovskiy, S. V., Syndergaard, S., Thompson, D. C., Trenberth, K. E., Wee, T.K., Yen, N. L., and Zeng, Z.: The COSMIC/FORMOSAT-3 mission: Early results, B. Am. Meteorol. Soc., 89, 313-333, https://doi.org/10.1175/BAMS-89-3-313, 2008.

Ao, C. O., Hajj, G. A., Meehan, T. K., Dong, D., Iijima, B. A., Mannucci, A. J., and Kursinski, E. R.: Rising and setting GPS occultations by the use of open-loop tracking, J. Geophys. Res., 114, D04101, https://doi.org/10.1029/2008JD010483, 2009.

Bai, W., Liu, C., Meng, X., Sun, Y., Kirchengast, G., Du, Q., Wang, X., Yang, G., Liao, M., Yang, Z., Zhao, D., Xia, J., Cai, Y., Liu, L., and Wang, D.: Evaluation of atmospheric profiles derived from single- and zero-difference excess phase processing of BeiDou System radio occultation data of the FY-3C GNOS mission, Atmos. Meas. Tech. Discuss., https://doi.org/10.5194/amt-2017177, in review, 2017.

Bates, J. J. and Privette, J. L.: A maturity model for assessing the completeness of climate data records, Eos, 93, 441-441, https://doi.org/10.1029/2012EO440006, 2012.

Beyerle, G., Schmidt, T., Michalak, G., Heise, S., Wickert, J., and Reigber, C.: GPS radio occultation with GRACE: Atmospheric profiling utilizing the zero difference technique, Geophys. Res. Lett., 32, L13806, https://doi.org/10.1029/2005GL023109, 2005.

Cucurull, L. and Derber, J. C.: Operational implementation of COSMIC observations into NCEP's global data assimilation system, Weather Forecast., 23, 702-711, https://doi.org/10.1175/2008WAF2007070.1, 2008.

Danzer, J., Scherllin-Pirscher, B., and Foelsche, U.: Systematic residual ionospheric errors in radio occultation data and a potential way to minimize them, Atmos. Meas. Tech., 6, 2169-2179, https://doi.org/10.5194/amt-6-2169-2013, 2013.

de la Beaujardière, O., Jeong, L., Basu, B., Basu, S., Beach, T., Bernhardt, P., Burke, W., Groves, K., Heelis, R., Holzworth, R., Huang, C., Hunton, D., Kelley, M., Pfaff, R., Retterer, J., Rich, F., Starks, M., Straus, P., and Valladares, C.: C/NOFS: a mission to forecast scintillations, J. Atmos. Sol.-Terr. Phy., 66, 1573-1591, https://doi.org/10.1016/j.jastp.2004.07.030, 2004.

European Centre for Medium-RangeWeather Forecasts (ECMWF) ECMWF analyses and short-range forecasts, available at: https: //www.ecmwf.int/en/forecasts/datasets, last access: 28 February 2017.

Foelsche, U., Borsche, M., Steiner, A. K., Gobiet, A., Pirscher, B., Kirchengast, G., Wickert, J., and Schmidt, T.: Observing upper troposphere-lower stratosphere climate with radio occultation data from the CHAMP satellite, Clim. Dynam., 31, 49-65, https://doi.org/10.1007/s00382-007-0337-7, 2008.

Foelsche, U., Scherllin-Pirscher, B., Ladstädter, F., Steiner, A. K., and Kirchengast, G.: Refractivity and temperature climate records from multiple radio occultation satellites consistent within $0.05 \%$, Atmos. Meas. Tech., 4, 2007-2018, https://doi.org/10.5194/amt-4-2007-2011, 2011.

GCOS: Implementation plan for the global observing system for climate in support of the UNFCCC (2010 update), GCOS138, update to GCOS-92, WMO-TD/No. 1523, WMO, Geneva, available at: http://www.wmo.int/pages/prog/gcos/Publications/ gcos-138.pdf, 2010a.

GCOS: Guideline for the Generation of Datasets and Products Meeting GCOS Requirements, GCOS-143, update to 
GCOS-128, WMO-TD/No. 1530, WMO, Geneva, available at: http://www.wmo.int/pages/prog/gcos/Publications/gcos- 143 . pdf, 2010b.

GCOS: Systematic Observation Requirements for Satellite-based Products for Climate (2011 Update), GCOS-154, supplement to GCOS-138, update to GCOS-107, WMO, Geneva, available at: http://www.wmo.int/pages/prog/gcos/Publications/gcos- 154 . pdf, 2011.

Gobiet, A. and Kirchengast, G.: Advancements of Global Navigation Satellite System radio occultation retrieval in the upper stratosphere for optimal climate monitoring utility, J. Geophys. Res., 109, D24110, https://doi.org/10.1029/2004JD005117, 2004.

Gobiet, A., Kirchengast, G., Manney, G. L., Borsche, M., Retscher, C., and Stiller, G.: Retrieval of temperature profiles from CHAMP for climate monitoring: intercomparison with Envisat MIPAS and GOMOS and different atmospheric analyses, Atmos. Chem. Phys., 7, 3519-3536, https://doi.org/10.5194/acp-7-35192007, 2007.

Gorbunov, M. E.: Canonical transform method for processing radio occultation data in the lower troposphere, Radio Sci., 37, 1076, https://doi.org/10.1029/2000RS002592, 2002.

Gorbunov, M. E. and Lauritsen, K. B.: Analysis of wave fields by Fourier integral operators and their application for radio occultations, Radio Sci., 39, RS4010, https://doi.org/10.1029/2003RS002971, 2004.

Hajj, G. A., Ao, C. O., Iijima, B. A., Kuang, D., Kursinski, E. R., Mannucci, A. J., Meehan, T. K., Romans, L. J., de la Torre Juarez, M., and Yunck, T. P.: CHAMP and SAC-C atmospheric occultation results and intercomparisons, J. Geophys. Res., 109, D06109, https://doi.org/10.1029/2003JD003909, 2004.

Healy, S. B. and Thépaut, J. N.: Assimilation experiments with CHAMP GPS radio occultation measurements, Q. J. Roy. Meteor. Soc., 132, 605-623, https://doi.org/10.1256/qj.04.182, 2006.

Ho, S.-P., Hunt, D., Steiner, A. K., Mannucci, A. J., Kirchengast, G., Gleisner, H., Heise, S., von Engeln, A., Marquardt, C., Sokolovskiy, S., Schreiner, W., Scherllin-Pirscher, B., Ao, C., Wickert, J., Syndergaard, S., Lauritsen, K., Leroy, S., Kursinski, E. R., Kuo, Y.-H., Foelsche, U., Schmidt, T., and Gorbunov, M.: Reproducibility of GPS radio occultation data for climate monitoring: Profile-to-profile inter-comparison of CHAMP climate records 2002 to 2008 from six data centers, J. Geophys. Res., 117, D18111, https://doi.org/10.1029/2012JD017665, 2012.

Kursinski, E. R., Hajj, G. A., Schofield, J. T., Linfield, R. P., and Hardy, K. R.: Observing Earth's atmosphere with radio occultation measurements using the Global Positioning System, J. Geophys. Res., 102, 23429-23465, https://doi.org/10.1029/97JD01569, 1997.

Leroy, S. S., Dykema, J. A., and Anderson, J. G.: Climate benchmarking using GNSS occultation, in: Atmosphere and Climate: Studies by Occultation Methods, edited by: Foelsche, U., Kirchengast, G., and Steiner, A. K., Springer, Berlin Heidelberg, 287-301, https://doi.org/10.1007/3-540-34121-8_24, 2006.

Li, Y., Kirchengast, G., Scherllin-Pirscher, B., Norman, R., Yuan, Y. B., Fritzer, J., Schwaerz, M., and Zhang, K.: Dynamic statistical optimization of GNSS radio occultation bending angles: advanced algorithm and performance analysis, Atmos. Meas. Tech., 8, 3447-3465, https://doi.org/10.5194/amt-8-3447-2015, 2015.
Liao, M., Zhang, P., Yang, G.-L., Bi, Y.-M., Liu, Y., Bai, W.H., Meng, X.-G., Du, Q.-F., and Sun, Y.-Q.: Preliminary validation of the refractivity from the new radio occultation sounder GNOS/FY-3C, Atmos. Meas. Tech., 9, 781-792, https://doi.org/10.5194/amt-9-781-2016, 2016.

Liu, C. L., Kirchengast, G., Zhang, K., Norman, R., Li, Y., Zhang, S. C., Fritzer, J., Schwaerz, M., Wu, S. Q., and Tan, Z. X.: Quantifying residual ionospheric errors in GNSS radio occultation bending angles based on ensembles of profiles from end-to-end simulations, Atmos. Meas. Tech., 8, 2999-3019, https://doi.org/10.5194/amt-8-2999-2015, 2015.

Luntama, J.-P., Kirchengast, G., Borsche, M., Foelsche, U., Steiner, A., Healy, S. B., von Engeln, A., O'Clerigh, E., and Marquardt, C.: Prospects of the EPS GRAS mission for operational atmospheric applications, B. Am. Meteorol. Soc., 89, 1863-1875, https://doi.org/10.1175/2008BAMS2399.1, 2008.

Melbourne, W. G., Davis, E. S., Duncan, C. B., Hajj, G. A., Hardy, K. R., Kursinski, E. R., Meehan, T. K., Young, L. E., and Yunck, T. P.: The application of spaceborne GPS to atmospheric limb sounding and global change monitoring, JPL Publication No. 9418, 147 pp., 1994.

Ohring, G., Wielicki, B., Spencer, R., Emery, B., and Datla, R.: Satellite Instrument Calibration for Measuring Global Climate Change: Report of a Workshop, B. Am. Meteorol. Soc., 86, 1303-1313, https://doi.org/10.1175/BAMS-86-9-1303, 2005.

Pirscher, B.: Multi-satellite climatologies of fundamental atmospheric variables from radio occultation and their validation, $\mathrm{PhD}$ thesis, Wegener Center Verlag Graz, Austria, Sci. Rep. 33-2010, 2010.

Pirscher, B., Foelsche, U., Borsche, M., Kirchengast, G., and Kuo, Y.-H.: Analysis of migrating diurnal tides detected in FORMOSAT-3/COSMIC temperature data, J. Geophys. Res., 115, D14108, https://doi.org/10.1029/2009JD013008, 2010.

Rieder, M. J. and Kirchengast, G.: Error analysis and characterization of atmospheric profiles retrieved from GNSS occultation data, J. Geophys. Res., 106, 31755-31770, 2001.

Scherllin-Pirscher, B., Kirchengast, G., Steiner, A. K., Kuo, Y.-H., and Foelsche, U.: Quantifying uncertainty in climatological fields from GPS radio occultation: an empiricalanalytical error model, Atmos. Meas. Tech., 4, 2019-2034, https://doi.org/10.5194/amt-4-2019-2011, 2011a.

Scherllin-Pirscher, B., Steiner, A. K., Kirchengast, G., Kuo, Y.-H., and Foelsche, U.: Empirical analysis and modeling of errors of atmospheric profiles from GPS radio occultation, Atmos. Meas. Tech., 4, 1875-1890, https://doi.org/10.5194/amt-4-1875-2011, $2011 b$.

Schreiner, W.: Constellation Observing System for Meteorology, Ionosphere, and Climate/FORMOSAT-3 (COSMIC/FORMOSAT-3): Ten Years of Science Highlights, Presentation at the OPAC-IROWG 2016 Workshop, Leibnitz, Austria, 8-14 September, 2016.

Schreiner, W., Rocken, C., Sokolovskiy, S., Syndergaard, S., and Hunt, D.: Estimates of the precision of GPS radio occultations from the COSMIC/FORMOSAT-3 mission, Geophys. Res. Lett., 34, L04808, https://doi.org/10.1029/2006GL027557, 2007.

Schreiner, W., Kuo, Y.-H., Ho, S.-P., Sokolovskiy, S., and Hunt, D.: Use of GNSS Radio Occultation data for Climate Applications, World Climate Research Program Conference, Denver, Colorado, USA, 24-28 October 2011, 
available at: http://www.cosmic.ucar.edu/groupAct/references/ WCRP-2011-Schreiner-Final.pdf,2011.

Schreiner, W. S., Rocken, C., Sokolovskiy, S., and Hunt, D.: Quality assessment of COSMIC/FORMOSAT-3 GPS radio occultation data derived from single- and double-difference atmospheric excess phase processing, GPS Solut., 14, 13-22, https://doi.org/10.1007/s10291-009-0132-5, 2010.

Schwarz, J.: Potential Systematic Errors in Radio Occultation Climatologies due to Irregular Distributions of Apparent Outliers in the Retrieval Process, Wegener Center Verlag Graz, Austria, Sci. Rep. No. 54-2013, 2013.

Schwarz, J. C., Kirchengast, G., and Schwaerz, M.: Integrating uncertainty propagation in GNSS radio occultation retrieval: from bending angle to dry-air atmospheric profiles, Earth Space Sci., 4, 200-228, https://doi.org/10.1002/2016EA000234, 2017.

Schwärz, M., Kirchengast, G., Scherllin-Pirscher, B., Schwarz, J., Ladstädter, F., and Angerer, B.: Multi-Mission Validation by Satellite Radio Occultation - Extension Project, Final report for ESA/ESRIN No. 01/2016, WEGC, University of Graz, Austria, 2016.

Smith, E. and Weintraub, S.: The constants in the equation for atmospheric refractive index at radio frequencies, Proc. IRE, 41, 1035-1037, 1953.

Steiner, A. K. and Kirchengast, G.: Error analysis of GNSS radio occultation data based on ensembles of profiles from end-to-end simulations, J. Geophys. Res., 110, D15307, https://doi.org/10.1029/2004JD005251, 2005.

Steiner, A. K., Lackner, B. C., Ladstädter, F., Scherllin-Pirscher, B., Foelsche, U., and Kirchengast, G.: GPS radio occultation for climate monitoring and change detection, Radio Sci., 46, RS0D24, https://doi.org/10.1029/2010RS004614, 2011.
Steiner, A. K., Hunt, D., Ho, S.-P., Kirchengast, G., Mannucci, A. J., Scherllin-Pirscher, B., Gleisner, H., von Engeln, A., Schmidt, T., Ao, C., Leroy, S. S., Kursinski, E. R., Foelsche, U., Gorbunov, M., Heise, S., Kuo, Y.-H., Lauritsen, K. B., Marquardt, C., Rocken, C., Schreiner, W., Sokolovskiy, S., Syndergaard, S., and Wickert, J.: Quantification of structural uncertainty in climate data records from GPS radio occultation, Atmos. Chem. Phys., 13, 1469-1484, https://doi.org/10.5194/acp13-1469-2013, 2013.

University Corporation of Atmospheric Research/COSMIC Data Analysis and Archive Center (UCAR/CDAAC): Atmospheric excess phase and orbit data, available at: http://cdaac-www. cosmic.ucar.edu/cdaac/products.html, last access: 28 February 2017.

Vorob'ev, V. V. and Krasil'nikova, T. G.: Estimation of the accuracy of the atmospheric refractive index recovery from Doppler shift measurements at frequencies used in the NAVSTAR system, Izv. Atmos. Ocean. Phys., 29, 602-609, 1994.

Wickert, J., Reigber, C., Beyerle, G., König, R., Marquardt, C., Schmidt, T., Grunwaldt, L., Galas, R., Meehan, T., Melbourne, W., and Hocke, K.: Atmosphere sounding by GPS radio occultation: First results from CHAMP, Geophys. Res. Lett., 28, 3263 3266, 2001.

Wickert, J., Beyerle, G., König, R., Heise, S., Grunwaldt, L., Michalak, G., Reigber, Ch., and Schmidt, T.: GPS radio occultation with CHAMP and GRACE: A first look at a new and promising satellite configuration for global atmospheric sounding, Ann. Geophys., 23, 653-658, https://doi.org/10.5194/angeo-23-6532005, 2005. 